\title{
Evaluation of a Telenutrition Weight Loss Intervention Among Middle-Aged and Older Men in Appalachia
}

\author{
Afnan Majed Alamoudi \\ afnan.alamoudi2012@hotmail.com
}

Follow this and additional works at: https://researchrepository.wvu.edu/etd

Part of the Human and Clinical Nutrition Commons

\section{Recommended Citation}

Alamoudi, Afnan Majed, "Evaluation of a Telenutrition Weight Loss Intervention Among Middle-Aged and Older Men in Appalachia" (2021). Graduate Theses, Dissertations, and Problem Reports. 10202. https://researchrepository.wvu.edu/etd/10202

This Thesis is protected by copyright and/or related rights. It has been brought to you by the The Research Repository @ WVU with permission from the rights-holder(s). You are free to use this Thesis in any way that is permitted by the copyright and related rights legislation that applies to your use. For other uses you must obtain permission from the rights-holder(s) directly, unless additional rights are indicated by a Creative Commons license in the record and/ or on the work itself. This Thesis has been accepted for inclusion in WVU Graduate Theses, Dissertations, and Problem Reports collection by an authorized administrator of The Research Repository @ WVU. For more information, please contact researchrepository@mail.wvu.edu. 


\title{
Evaluation of a Telenutrition Weight Loss Intervention Among Middle-Aged and Older Men in Appalachia
}

\author{
Afnan Majed Alamoudi
}

Thesis submitted to the Davis College of Agriculture, Natural Resources and Design at West Virginia University

\author{
In partial fulfillment of the requirements for the degree of \\ Master of Science \\ In Nutritional and Food Science
}

\author{
Melissa Ventura-Marra, PhD, RDN, Chair \\ Ida Holásková, PhD \\ Dina L. Jones, PT, PhD \\ Department of Animal and Nutritional Sciences \\ Morgantown, West Virginia \\ 2021
}

Keywords: telehealth; telenutrition; evaluation; obese; weight loss; intervention; middle-aged;

older; men; adults

Copyright 2021 Afnan Majed Alamoudi 


\title{
ABSTRACT \\ Evaluation of a Telenutrition Weight Loss Intervention Among Middle-Aged and Older Men in Appalachia
}

\begin{abstract}
Afnan Majed Alamoudi
Obesity rates among middle-aged and older men in WV are among the highest in the nation. Understanding baseline and intervention factors contributing to losing clinically significant weight are essential to developing effective interventions in target groups. Thus, the purpose of this study is to determine factors associated with losing $\geq 5 \%$ of baseline weight among participants of a 12week pilot randomized controlled telenutrition trial for middle-aged and older men in WV. The study analyzed data from 56 participants who completed the trial. Participants were classified as losing $\geq 5 \%$ or $<5 \%$ of baseline body weight. Diet quality was assessed using 4-day diet records and the Healthy Eating Index (HEI)-2015. Baseline factors and behavioral strategies (i.e., selfmonitoring, self-efficacy, and social support) were assessed via survey. Inverse prediction analysis demonstrated that participants who lost $\geq 3.5 \%$ of baseline weight at 6 weeks were at least $75 \%$ likely to lose $\geq 5 \%$ weight at 12 weeks. Predictive models were developed using stepwise logistic regression to assess multiple predictors of losing $\geq 5 \%$ of baseline weight at 12 weeks and $\geq 3.5 \%$ of baseline at 6 weeks. Weight loss at 6 weeks was a strong predictor of weight loss at 12 weeks, in addition to previous weight loss attempts and weekly self-weight-monitoring $(\mathrm{p}<0.05)$. Specifically, a greater probability of losing $\geq 5 \%$ of baseline weight at 12 weeks was estimated for participants who: always self- monitored weekly weight (odds ratio (OR) 34), did not attempt other weight loss programs in the past (OR 64), and had lost weight at 6 weeks (OR 5 for one percent increase in weight loss at 6 weeks). Analysis of factors leading to the $\geq 3.5 \%$ baseline weight loss at 6 weeks detected that increasing HEI change score at 6 weeks (OR 1.1 for each one-unit increase of HEI), and report of a family starting to eat better (OR 5) were influential. These findings suggest that for middle-aged men with obesity, early weight loss is important to losing $\geq 5 \%$ of baseline weight at the end of the intervention. The results support the use of behavioral strategies such as increased self-monitoring of weekly weight and focusing on healthier eating for the whole family, as these factors were related to better weight loss outcomes at the end of the intervention. Participants should be encouraged to self-monitor their weekly weights and dietary intake and be provided strategies to help them adhere to a high-quality diet in future interventions.
\end{abstract}




\section{ACKNOWLEDGMENTS}

First, I would like to thank ALLAH for providing me with the physical and mental strength to continue this work and accomplish my Master of Science Degree in Nutritional and Food Science from a recognized department in West Virginia University. I would like to express my gratitude to my advisor Dr. Melissa Marra for her endless support and guidance as a mentor for the project and her continued encouragement and assistance throughout my master's degree to make this happen. Also, I would like to thank my committee members, Dr. Ida Holásková, for all the time and assistance she gave me to finish my project's statistical analysis and interpretation. Additionally, I would like to thank Dr. Dina Jones for her helpful feedback and support. Also, throughout my graduate years at WVU, I was lucky to receive support and guidance from many faculty members. I want to express my thankfulness to everyone who has allowed me to benefit from their enormous knowledge. I would also like to thank WVU research assistants for their contributions to data collection in the Telenutrition Weight Loss Intervention study that made my thesis possible. Also, I would like to thank my beloved parents for their moral and emotional support and encourage me to continue studying. Especial thanks to my lovely husband "Mohammed" and my son "Tariq" for their patience and relieving my stresses. Finally, I'm grateful to my government, represented by the Saudi Arabian Cultural Mission (SACM), for providing the essential financial support to complete my degree at WVU. 


\section{TABLE OF CONTENT}

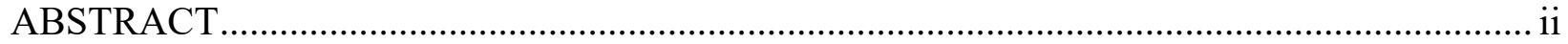

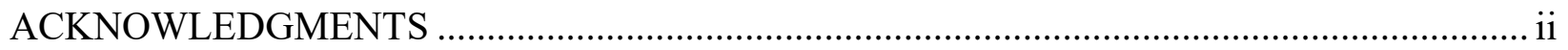

TABLE OF CONTENT …………………………............................................................. iv

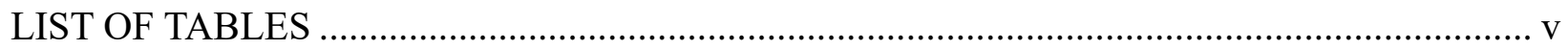

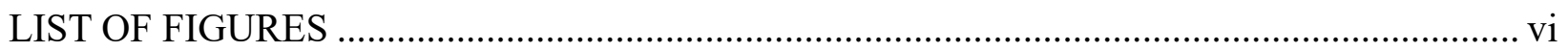

LIST OF ABBREVIATIONS …………………......................................................... vii

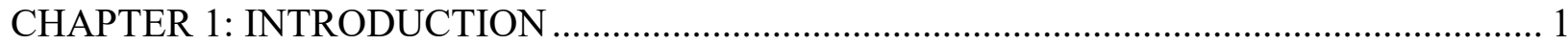

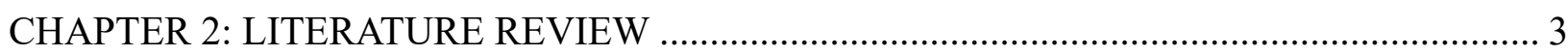

Evidence-Based Intervention Components ........................................................................ 3

Intervention Components and Weight Loss Outcomes............................................................. 3

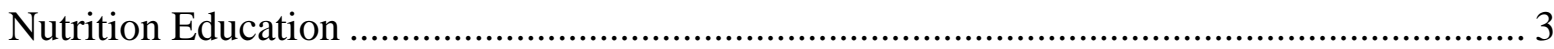

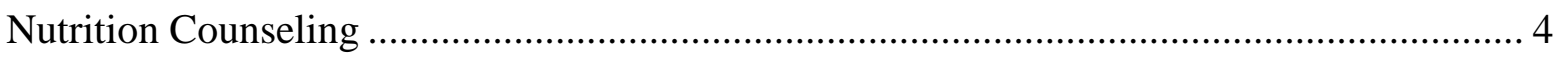

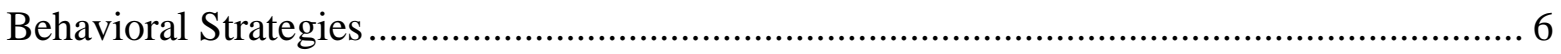

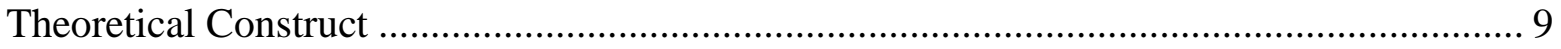

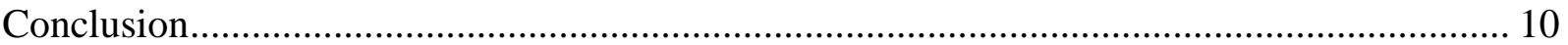

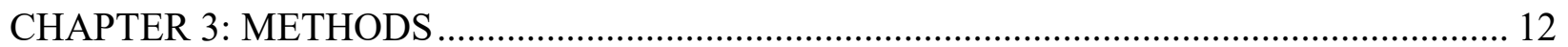

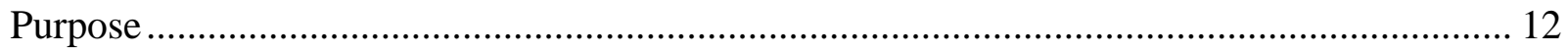

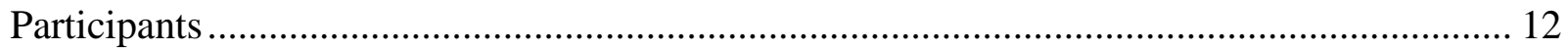

Intervention Design and Components .............................................................................. 12

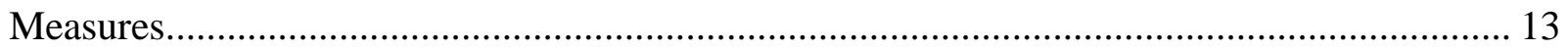

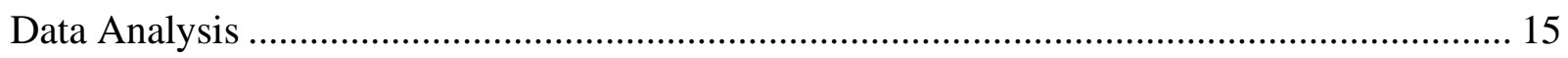

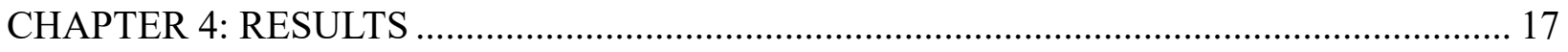

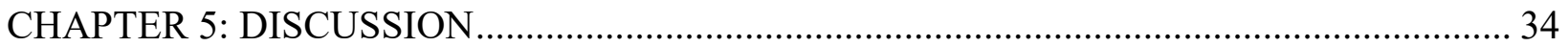

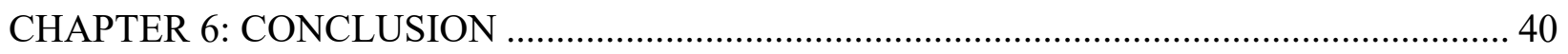

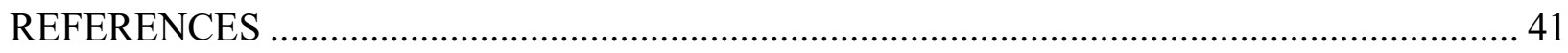

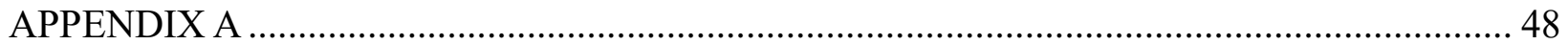




\section{LIST OF TABLES}

Table 1. Baseline characteristics of participants who completed the telenutrition weight loss intervention program by weight loss group at 12 weeks.

Table 2. Intervention component characteristics of participants who completed the telenutrition weight loss intervention program by weight loss group at 12 weeks.

Table 3. RDN behavioral support for participants in the telenutrition intervention group only $(\mathrm{n}=27)$

Table 4. Bivariate analysis of the percentage of weight loss at 12 weeks (Categorical ) ......... 24

Table 5. Multivariate analysis for all factors potentially affecting participants lost $\geq 5 \% /<5 \%$ weight loss at 12 weeks (Categorical) including the $\%$ weight loss changes at 6 weeks ${ }^{1}$....... 27

Table 6 . Alternative multivariate analysis for all factors potentially affecting participants lost $\geq 5 \% /<5 \%$ weight loss at 12 weeks (Categorical) without the variable $\%$ weight loss changes at 6 weeks ${ }^{1}$...... 28

Table 7. Bivariate analysis of the percentage of weight loss at 6 weeks (Categorical) by baseline characteristics of participants who completed the telenutrition weight loss intervention program.

Table 8. Bivariate analysis of the percentage of weight loss at 6 weeks (Categorical) by Intervention Component potentially affecting if a participant lost weight

Table 9. Multivariate analysis for all factors potentially affecting participants lost $\geq 3.5 \% /<$ $3.5 \%$ weight loss at 6 weeks (Categorical) ${ }^{1}$

Table A 1. Bivariate analysis of the percentage of weight loss at 6 and 12 weeks (continuous variables) by baseline characteristics of participants who completed the telenutrition weight loss intervention program.

Table A 2. Bivariate analysis of the percentage of weight loss at 6 and 12 weeks (continuous variables ) and by Intervention Component potentially affecting if a participant lost weight.. 51 Table A 3. Multivariate analysis for all factors potentially affecting participants the percentage weight loss at 6 weeks (Continuous) 1

Table A 4. Multivariate analysis for all factors potentially affecting participants the percentage weight loss at 12weeks (Continuous) with \% weight loss changes at 6 weeks 1 ..................... 55

Table A 5. Multivariate analysis for all factors potentially affecting participants the percentage weight loss at 12weeks (Continuous) without $\%$ weight loss changes at 6 weeks 1 ................ 56

Table A 6. Bivariate analysis of dietary outcomes (HEI) by baseline characteristics potentially affecting if a participant lost weight. 57

Table A 7. Bivariate analysis of dietary outcomes (HEI) by intervention components potentially affecting if a participant lost weight. 


\section{LIST OF FIGURES}

Figure 1. Matched pairs on HEI change at 6 and 12 weeks ........................................... 21

Figure 2. Repeated measures on total HEI score at 0,6 and 12 weeks ............................... 22

Figure 3. Repeated measures on FFMI at 0,6 and 12 weeks......................................... 22

Figure 4. Prediction of percentage weight change at 6 week to lose $\geq 5 \%$ of baseline weight at

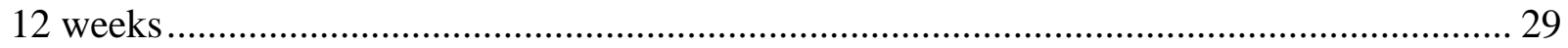




\section{LIST OF ABBREVIATIONS}

Academy of Nutrition and Dietetics

Academy

Action for Health in Diabetes

AHEAD

American College of Cardiology

ACC

American Heart Association

AHA

Australian Recommended Food Score

ARFS

Body Mass Index

BMI

Cardiovascular Disease

CVD

Cardiovascular Lifestyle Program

CLIP

Diabetes Prevention and Management

DPM

Diabetes Prevention Program

DPP

Dietary Intervention Randomized Controlled Trial

DIRECT

Enhanced Usual Care

EUC

Evidence Analysis Library's

EAL

Fat Free Mass Index

FFMI

Healthy Eating Index-2015

HEI

Medical Nutrition Therapy

MNT

Multi-Frequency Bioelectrical Impendence Analysis

MF-BIA

Nutrition Data Systems for Research

NDSR

Randomized Controlled Trial

RCT

Recovering Energy Through Nutrition and Exercise for Weight Loss

RENEW

Registered Dietitian Nutritionist

RDN

Research Electronic Data Capture

REDCap

Support, Health Information, Nutrition, and Exercise

SHINE

The Obesity Society

TOS

United States

US

West Virginia

WV

West Virginia University

WVU

World Health Organization

WHO 


\section{CHAPTER 1: INTRODUCTION}

In the United States (US), the prevalence of obesity is $42.4 \%$ among adults and $46.4 \%$ among middle-aged men. ${ }^{1}$ In West Virginia (WV), obesity rates are the second-highest in the nation, ${ }^{2}$ and prevalence of overweight or obesity is highest among 45-54 year old men. ${ }^{3}$ Obesity is a risk factor for several chronic conditions, including type 2 diabetes, cardiovascular disease (CVD), stroke, and some cancers. ${ }^{4}$ The high prevalence of obesity in WV and the related health consequences make it necessary to increase access to weight-loss interventions in at-risk populations. Telehealth is one way to improve access to weight-management programs in rural areas.

The development of nutrition interventions should include information from evaluating successful programs. The most useful types of evaluation for nutrition interventions include formative, process, and outcome evaluations. ${ }^{5}$ Some study evaluations have identified essential components of weight loss intervention programs and body weight outcomes as nutrition educational materials, ${ }^{6,7}$ nutrition education and counseling with the Registered Dietitian Nutritionist (RDN) through Medical Nutrition Therapy (MNT) encounters ${ }^{8-10}$ and telephone health coaching calls, ${ }^{11,12}$ self-monitoring weekly weight ${ }^{13,14}$ and diet, ${ }^{15,16}$ goal-setting, ${ }^{17,18}$ social support, ${ }^{17,18}$ and self-efficacy. ${ }^{19,20}$ However, there remains a need to identify essential components of nutrition interventions that target specific population sub-groups.

In 2016, a pilot randomized controlled trial (RCT) of a telenutrition weight loss intervention program in obese men was conducted to assess the feasibility and effectiveness of the program. ${ }^{21}$ The study found that the telenutrition program successfully reduced calorie consumption and body weight and increased diet quality. Identifying the essential components of a weight loss intervention program is vital to achieving improved weight outcomes and to better 
inform future trials for this population. Also, because there is a variation in an individual's response to weight loss intervention, it is essential to determine which factors influence participant success. Hence, the purpose of this study is to evaluate baseline and intervention factors in a telenutrition weight loss intervention program to determine which factors were associated with participants losing clinically significant weight loss of $\geq 5 \%$ of baseline weight at 12 weeks among middleaged and older men. 


\section{CHAPTER 2: LITERATURE REVIEW}

\section{Evidence-Based Intervention Components}

Evidence-based guidelines recommend key components of a comprehensive lifestyle intervention for adults with overweight/obesity. ${ }^{22-25}$ Evidence-based recommendations for weight loss are available from the 2013 American Heart Association/American College of Cardiology/The Obesity Society Guideline for the Management of Overweight and Obesity in Adults (the AHA/ACC/TOS guidelines). ${ }^{22}$ The guidelines recommend that weight-loss interventions include an energy-restricted diet and behavioral therapy strategies. ${ }^{22}$ Creating an energy deficit through caloric restriction can be achieved in three ways: 1) dietary intake of 1200-1500 kcal/d for women and $1500-1800 \mathrm{kcal} / \mathrm{d}$ for men, 2) $500-750 \mathrm{kcal} /$ day below the estimated requirement, or 3) use one of the evidence-based diets that restrict certain types of food. ${ }^{22}$ Some common behavioral therapy strategies include self-monitoring, ${ }^{22-25}$ goal setting, ${ }^{23-25}$ social support, ${ }^{23,24}$ self-efficacy, ${ }^{25}$ problem-solving and preplanning, ${ }^{24,25}$ cognitive restructuring, ${ }^{24,25}$ stimulus control, ${ }^{24}$ and relapse prevention. ${ }^{24}$

\section{Intervention Components and Weight Loss Outcomes}

\section{Nutrition Education}

The Academy of Nutrition and Dietetics (Academy) defines nutrition education as a formal process to instruct or train clients in a skill or impart knowledge to help clients voluntarily manage or modify food, nutrition, and physical activity choices and behavior to maintain or improve health. ${ }^{26}$ Nutrition education content is defined as the instruction or training intended to increase nutrition-related knowledge. ${ }^{26}$ Studies have examined the association between knowledge and weight reduction in various populations. Klohe-Lehman et al. ${ }^{6}$ assessed if more nutrition knowledge helped increase weight loss in overweight and obese low-income mothers in an 8-week weight loss intervention. Participants with weight loss of $\geq 2.27 \mathrm{~kg}$ had more nutrition knowledge 
than those losing $<2.27 \mathrm{~kg}$. However, both groups gained nutrition knowledge. Jeffery and Wing ${ }^{7}$ found an increase in nutrition knowledge after 18 months in the behavioral weight-loss program of 177 older men and women with obesity. Weight loss was positively correlated with increases in knowledge. Hence, weight management programs should include nutrition education as a vital component to increase dietary knowledge to promote effective weight control.

\section{Nutrition Counseling}

One of the crucial strategies to help treat individuals with obesity is to provide nutrition counseling focused on diet change. ${ }^{27}$ Dietitians are trained nutrition professionals ideally suited to provide nutrition counseling in obesity treatment programs. ${ }^{28}$ Dietitians may provide nutrition education and counseling-related services through telenutrition. According to the Academy, telenutrition is evidence-based MNT by an RDN using interactive electronic information and telecommunications technology such as videoconference with patients at a remote location. ${ }^{29}$ According to the Academy's Evidence Analysis Library, there are a significant enhancement in body weight, body mass index (BMI), A1C, blood pressure, and serum lipids when an RDN offered the telenutrition interventions and counseling. ${ }^{30}$

MNT Encounters. There are many advantages to providing face-to-face encounters through videoconferencing. Practitioners can respond to verbal and non-verbal cues from the patient, build rapport, and provide customized feedback to encourage lifestyle and behavior changes. ${ }^{31}$ Additionally, some studies showed is the impacts of including live videoconferencing with an RDN to deliver health coaching and lifestyle modification on weight loss intervention programs. ${ }^{12-14,37,38}$

Alencar et al. ${ }^{8}$ examined the effectiveness of a telehealth weight loss program incorporating health coaching via videoconferencing by an RDN for 12-week on weight loss. They found that 
average weight loss was $7.16 \pm 4.4 \%$ in the videoconferencing group and $1.5 \pm 4.1 \%$ in the control group. Similarly, Johnson et al. ${ }^{32}$ showed that participants in the videoconferencing group $(8.23 \pm$ $4.5 \mathrm{~kg} ; 7.7 \%$ ) which received individualized health coaching, including encounters with an RDN, lost more weight than the in-person group $(3.2 \pm 2.6 \mathrm{~kg} ; 3.4 \%)$ and control group $(2.9-3.9 \mathrm{~kg}$; 3.3\%) over the 12-week intervention. Also, Ahrendt et al. ${ }^{9}$ indicated that participants who received classes with an RDN lost on average $3.4 \pm 0.5 \mathrm{~kg}$ of body weight while the control group gained weight, resulting in a mean difference between the groups of $-5.5 \pm 2.7 \mathrm{~kg}(95 \% \mathrm{CI}=-8.0$ to -3.0 ; $\mathrm{P}<.0001)$. However, some studies showed no differences in the percentage of body weight lost between the videoconferencing and control or in-person groups. Taetzsch et al. ${ }^{10}$ found that participants in videoconferencing and in-person groups lost body weight over the 12-week intervention. However, there was no difference between the groups [in-person group (6.2 $\pm 3.2 \%)$ and videoconferencing group $(5.3 \pm 3.4 \%)]$. Another study by Vadheim et al. ${ }^{33}$ showed that telehealth by an RDN resulted in weight loss outcomes $(6.7 \pm 3.7 \mathrm{~kg})$ similar to on-site group participants $(6.5 \pm 3.1 \mathrm{~kg})$, with over $45 \%$ of both groups were achieve the $7 \%$ weight loss goal. Overall, weight loss studies that include videoconferencing with an RDN have been effective.

Telephone Health Coaching Calls. One approach recently used in interventions to increase patient access to healthcare is telephone health coaching. Studies including telephone coaching showed enhancement in metabolic syndrome parameters, weight loss, and health behavior. ${ }^{12,34,35}$ Telephone-based weight loss interventions had many advantages, including providing participants with a personalized diet plan, behavioral modifications, urging them to weigh themselves, and reporting to the coach during the program. Hence, telephone health coaching could help reach a more significant number of participants. ${ }^{12,35}$ 
Although many studies have examined the impact of telephone health coaching interventions on weight loss, few studies used a dietitian to deliver the intervention. ChadFriedman et al. ${ }^{11}$ examined the use of telephone coaching in weight loss intervention with an RDN on body weight, blood pressure, stress, and health behaviors in obese patients. After participating in the program, participants lost a moderate weight and improved behavioral eating patterns, physical activity, and eating habits. Another study was conducted by Weinstock et al. ${ }^{12}$ on adults with obesity and metabolic syndrome without diabetes called SHINE (Support, Health Information, Nutrition, and Exercise). SHINE is a telephone adaptation of the Diabetes Prevention Program (DPP) intensive lifestyle program. They concluded that the program successfully attained significant weight loss at 1 and 2 years. After the second year, they found 52\% and $43 \%$ of participants in group calls lost at least $5 \%$ and $7 \%$ of their initial body weight, respectively, while for individual calls, $29 \%$ of participants lost $5 \%$, and $22 \%$ lost $7 \%$. However, a study in Australia ${ }^{36}$ evaluated the primary prevention care model using a telephone-supported intervention by an RDN in the Cardiovascular Lifestyle Program to prevent CVD. The results of this study indicate significant reductions in LDL-C and total cholesterol, but there were no significant changes in weight loss.

\section{Behavioral Strategies}

Self-Monitoring. Self-monitoring is the cornerstone of behavioral obesity treatment. ${ }^{22}$ It is a technique of recording and self-observing certain behaviors to improve self-awareness. ${ }^{37}$ Two systematic reviews showed that more significant weight loss in behavioral weight-loss interventions was associated with commitment to self-monitoring weight-related behaviors (i.e., diet, weight, and physical activity). ${ }^{38,39}$ 
The AHA/ACC/TOS guidelines recommended self-monitoring of weight (self-weighing) to manage overweight and obese adults. ${ }^{22}$ Regular self-weighing (e.g., daily, weekly) has many benefits. One of these benefits is that it can help people observe weight changes and recognize specific eating or physical activity patterns and how they impact body weight. ${ }^{40}$ Additionally, people may be motivated to change behavior after observing positive outcomes. ${ }^{41}$ Therefore, some studies demonstrated that weekly weighing was associated with significant weight loss. A prospective cohort study by VanWormer et al. ${ }^{13}$ found that the percentage of participants who lost $\geq 5 \%$ of their pretreatment weight were significantly higher among participants who self-weighed at least weekly (46\%) than those who self-weighed less than weekly $(8 \%)(\mathrm{OR}=11.1[3.0,41.2]$, $\mathrm{p}<0.001)$. Another study was done by Vanwormer et al. ${ }^{14}$ in 2012 among working adults. Results showed that daily and weekly weight self-weighing was significantly associated with weight change at 24-months follow-up. Also, participants lost more weight with daily and weekly weighing (1.8 $\mathrm{kg}$ and $0.9 \mathrm{~kg}$, respectively) than participants who reported self-weighing only monthly. Lally et al. ${ }^{42}$ reported no differences between weekly and monthly weighing in their study. Furthermore, a systematic review of self-weighing in weight management in 2014 by Zheng et al. $^{43}$ reviewed the evidence of the associations between regular self-weighing (e.g., daily, weekly) and weight change. Based on the review, regular self-weighing was associated with successful weight loss, weight maintenance, and weight gain prevention in adults seeking behavioral weight loss treatment.

Dietary self-monitoring involves recording all foods and beverages consumed, the portion size, and the preparation method. Regular dietary tracking of food and beverage intake is related to successful short and long-term weight loss. In a 6-month study of individuals who were overweight or obese $(n=1,685)$, increased adherence to dietary tracking (number of food records 
kept per week) was associated with significant weight loss $(5.8 \pm 4.4 \mathrm{~kg})$, and $69 \%$ of participants lost at least $4 \mathrm{~kg} .{ }^{15} \mathrm{~A}$ study by Ingels et al. ${ }^{16}$ examined the impact of adherence to dietary tracking on weight loss in a Diabetes Prevention and Management (DPM) program. The results showed that only consistent trackers ( $>66 \%$ days tracked) had significant weight loss ( -9.99 pounds) with consistent weight loss throughout the year. These results show the importance of frequent dietary tracking for consistent long-term weight loss success. Recently, Tronieri et al. ${ }^{44}$ found that complete commitment to dietary self-monitoring was significantly associated with a weight reduction of $7.2 \%(95 \% \mathrm{CI}-10.4$ to $-4.0 ; \mathrm{p}<0.0001)$ compared to non-adherence. In summary, dietary tracking is an essential component of a successful weight loss program.

Goal-Setting. Goal-setting is an activity that requires collaboration between a client and a dietetics practitioner..$^{45}$ Clients choose from potential actions that they want to accomplish and reach ${ }^{45}$ It is a suitable method for people ready to make behavior change by helping them set realistic and timely goals and help them obtain the necessary knowledge and skills for goal achievement. ${ }^{46}$

A systematic review was conducted to examine goal setting as a behavior change strategy for weight loss and behavior modification in overweight and obese adults. The study found that interventions focusing on goal-setting helped behavior change, including decreased weight, BMI levels, food and beverage consumption, and increased energy expenditure. ${ }^{47}$ Some studies examined the impact of weight loss intervention programs, including goal-setting strategies, on outcomes. Brown et al. ${ }^{48}$ studied a weight loss intervention for people with serious mental illness called RENEW (Recovering Energy Through Nutrition and Exercise for Weight Loss). The participants were randomly assigned to either the intervention or a control group based on the type of psychiatric medication. The intervention group received weekly nutrition instructions, including 
goal-setting. Twenty-eight percent of participants in the RENEW intervention group lost $5 \%$ of their body weight compared to only $5 \%$ of participants in the control group. These results indicate that using goal-setting as a behavior change strategy is helpful for weight loss in overweight and obese adults.

Social Support. Social support includes using family, friends, colleagues, and health professionals for information, encouragement, emotional support, and enhancing the environment to support behavior change. ${ }^{45}$ Some studies have examined the association between social support and weight management to determine if more support leads to better outcomes. There is a positive relationship between friends and family members' social support and weight loss in weight gain prevention trials and weight loss studies. ${ }^{49,50}$ Golan et al. ${ }^{17}$ examined the spouses' effect of a 2year weight-loss diet trial, the Dietary Intervention Randomized Controlled Trial (DIRECT), on participants' spouses' weight and nutritional patterns. A significant dietary weight loss was achieved at 6 months if a spouse also enrolled in a weight loss program $(-5.2 \mathrm{~kg})$ compared to if the spouse did not participate $(-3.5 \mathrm{~kg})$ in these sessions $(\mathrm{p}=0.020)$. Another study found that participants who had attended meetings with their spouses lost significantly more weight than participants who had participated without their spouses at 1 and 2-year follow-ups. ${ }^{18}$ However, a systematic review of family involvement in weight control by McLean et al ${ }^{51}$ found mixed results for spouse's involvement. Even though support from the spouse is often helpful, some studies showed that involvement from a close life partner is not always positive and can, for some, even interfere with the outcome..$^{52-54}$

\section{Theoretical Construct}

Self-Efficacy. Many health behavior change theories include self-efficacy as a critical construct. ${ }^{55}$ This construct might be characterized as a person's belief in his/her ability to perform 
a given activity. ${ }^{56}$ According to these theories, improving self-efficacy is a fundamental technique for increasing the adoption of particular health behavior. ${ }^{57}$ Many studies have shown the association between self-efficacy and change in weight over time. ${ }^{19,20,58}$

Self-efficacy was a significant predictor of weight loss at the 6-week and 6-month time points in a study of overweight women who participated in a weight reduction program. ${ }^{58}$ Palmeira et al. ${ }^{19}$ investigated weight loss differences depending on four health behavior change theories and discovered that theories that incorporated self-efficacy were better able to predict weight change than theories that did not. A study by Roach et al., ${ }^{20}$ which examined using self-efficacy among young adults, found that eating habits improved and weight loss was more significant if selfefficacy improved. These studies support that using behavioral techniques to improve self-efficacy can effectively produce weight loss and positive outcomes.

On the other hand, other research studies failed to show a link between increased selfefficacy and weight change. Throughout a 14 -week intervention, Fontaine and Cheskin ${ }^{59}$ discovered no association between self-efficacy and weight loss. Martin et al. ${ }^{60}$ found a negative association between self-efficacy and weight reduction. People who had more self-efficacy ratings lost less weight than those with lower self-efficacy scores.

\section{Conclusion}

Evidence from the reviewed literature suggests an association between diet, behavioral strategies, and theoretical constructs, and weight loss. The elements previously shown to help people lose weight are: nutrition educational materials,,${ }^{6,7}$ nutrition education and counseling with the RDNs through MNT encounters ${ }^{8-10}$ and telephone health coaching calls, ${ }^{15,16}$ self-monitoring weekly weight ${ }^{17,18}$ and diet, ${ }^{15,16}$ goal-setting, ${ }^{17,18}$ social support especially spouse support, ${ }^{17,18}$ and 
self-efficacy. ${ }^{19,20}$ Thus, using these techniques in weight loss intervention programs may effectively produce desirable weight loss outcomes. 


\section{CHAPTER 3: METHODS}

\section{Purpose}

The purpose of this study is to determine baseline and intervention factors associated with clinically significant weight loss ( $\geq 5 \%$ of baseline weight) among middle-aged and older men participating in a 12-week telenutrition weight loss intervention in WV.

\section{Participants}

Data from online questionnaires and nutrition counseling sessions with the RDN were analyzed for 56 participants who completed the 12-week RCT of a telenutrition weight loss intervention. The West Virginia University (WVU) Institutional Review Board approved the protocol which was registered at http://clinicaltrials.gov (NCT02938897). All participants provided informed consent. The study's eligibility criteria included being 40 to 70 years old, having a $\mathrm{BMI} \geq 30$, and having a diagnose of at least 1 of the following conditions: hypertension, hyperlipidemia, pre-diabetes, or diabetes. Details of the recruitment are detailed elsewhere. ${ }^{21}$

For this analysis, 2 groups were formed based on whether or not participants lost $\geq 5 \%$ of baseline weight at 12 weeks. Those who lost $<5 \%$ of baseline weight or gained weight at week 12 were categorized as the stable weight group; those who lost $\geq 5 \%$ were categorized as the weight loss group. Weight loss $\geq 5 \%$ is considered clinically significant weight loss. ${ }^{22}$

\section{Intervention Design and Components}

In the parent RCT, all participants $(n=56)$ received the following: an individualized reduced-calorie diet $(500-750 \mathrm{kcal} /$ day below their estimated requirement, diet-related educational materials (i.e., building a healthy plate, making smart beverage choices, and meal planning tips), and self-monitoring tools (e.g., fruit and vegetable tracker, shopping list, and weekly meal planner). Only participants randomly assigned to the telenutrition group $(n=27)$ received nutrition 
counseling support from an $\mathrm{RDN}^{21}$ An RDN provided the weekly support through 3 MNT encounters via videoconferencing sessions held at weeks 1,5 , and 9 during the study. The RDN encounters included a nutrition assessment, education, and counseling based on their diet history, perceived barriers, medical diagnoses, and laboratory values. They also received 9 nutritioncoaching sessions via telephone calls that were offered between weeks $2-4,6-8$, and 10-12.

\section{Measures}

All participants completed assessments at baseline weeks 0, 6, and 12. Each assessment period included an in-person visit and the completion of online questionnaires distributed via Research Electronic Data Capture (REDCap), a secure web-based application designed to support data capture for research studies and hosted at WVU. ${ }^{61}$

\section{Demographics}

At week 0, participants completed an online demographic questionnaire. They selfreported age in years, ethnicity, race, education level, work status, and income level.

\section{Health-related condition}

Nursing staff obtained baseline medical diagnoses (i.e., hypertension, pre-diabetes or diabetes, and hyperlipidemia) from the participants' medical records. The baseline survey included questions about smoking status, general health condition, and physical activity level.

\section{Anthropometric and body composition}

One research staff member, blinded to group assignment, collected all anthropometric and body composition measurements at weeks 0,6 , and 12 . Height was measured to the nearest $0.1 \mathrm{~cm}$ using the Seca 274 digital stadiometer (Seca, Hamburg, Germany) at the baseline assessment. Weight change was calculated in kilograms and percent reduction in body weight from baseline to week 6 and from baseline to week 12. BMI was calculated as weight $(\mathrm{kg}) /$ height $\left(\mathrm{m}^{2}\right)$ and classified 
using World Health Organization (WHO) classifications. ${ }^{62}$ Weight and Fat-Free Mass Index (FFMI) were determined using the Seca medical Bioelectrical Composition Analyzer (mBCA) 514 (Seca, Hamburg, Germany) and Seca analytics 115 PC software (Seca, Hamburg, Germany).

\section{Diet Assessment}

Self-reported dietary intake was assessed using 4-day (3 weekdays and 1 weekend day) diet records completed at the study time point. NDSR (Nutrition Data Systems for Research) software developed by the University of Minnesota Nutrition Coordinating System was used to examine the foods and beverages' nutritional content (NDS-R. Version 2010. Minneapolis, MN: Nutrition Coordinating Center; 2010). The Healthy Eating Index-2015 $5^{63}$ (HEI) was used to evaluate diet quality. The overall HEI score ranges from 0 to 100 , with higher values indicating better compliance with the Americans' 2015-2020 Dietary Guidelines. Change on the HEI score was calculated as the difference between the baseline and total scores at week 6 and 12 .

\section{Intervention Factors}

Data for baseline factors (i.e., weight and diet history, eating out frequency) and behavioral strategies or constructs (i.e., self-monitoring, self-efficacy, and social support) were collected by survey. The surveys asked a total of 2 questions to assess self-monitoring of diet and 2 questions to assess self-monitoring of weekly weight. For self-monitoring of weekly weight, participants' responses were classified as always (all 12 weeks weights were recorded), sometimes (less than 12 weeks weights were recorded), or never (no weights were recorded).

Participants were asked a total of 3 questions to evaluate self-efficacy (i.e., confidence in adhering to the recommendations in the Playbook, confidence they understood what changes they needed to make to lose weight and eat healthier, and confidence in their ability to make the necessary changes to eat healthier and lose weight). The responses were in the form of a 3-point 
Likert-like scale ranging from "agree" to "disagree," which was collapsed into 2 groups for the analysis "agree" or "disagree and neutral." To evaluate social support, participants were asked 6 questions related to social support they received from their spouse, family, friends, and doctors.

\section{RDN Behavioral Support (Intervention Group Participants)}

The RDN monitored the duration of the 3 MNT encounters (at weeks 1, 5, and 9) and the 9 health coach calls (offered between weeks $2-4,6-8$, and 10-12), the number of missed calls, and the most frequent goal topics selected by participants. Data were used to assess the total number of health coach calls, average health coach call (minutes), the total time with an RDN for both the MNT and the health coach calls, and the percentage of different SMART (Specific, Measurable, Attainable, Realistic, Time-bound) goals met.

\section{Data Analysis}

All statistical analyses were conducted using JMP software (JMP®, Version Pro 16.0.0, SAS Institute Inc., Cary, NC, 2021). Missing data were treated analytically with pairwise deletion. The Likert-like scale for some independent categorical variables was consolidated by combining neighboring levels due to either lack of counts of participants in certain levels or increased statistical power of tests. Categorical variables were described as $\mathrm{N}(\%)$, and continuous variables were reported as means \pm standard deviations. Repeated measures ANOVA was done at 3-time points (baseline, week 6, and week 12) for HEI total scores and FFMI; the 3-time points were compared using Tukey-Kramer adjustment. Matched pairs analysis was done on the pairs of observations of HEI change from the baseline (at 6 and 12 weeks). Bivariate analyses were performed to determine the relationship between baseline characteristics, weight/body composition, and dietary factors, as well as behavioral strategies/constructs factors with categorical weight loss at 12 weeks ( $<5 \%$ and $\geq 5 \%$ loss of baseline weight) and categorical weight 
loss at 6 weeks $(<3.5 \%$ and $\geq 3.5 \%$ loss of baseline weight). The type of the independent variable determined the analysis. For continuous independent variables, logistic regression was used. In the case of categorical independent variables (nominal and ordinal), nominal logistic regression was conducted utilizing the likelihood ratio test. Unless otherwise noted, statistical significance was defined at $\alpha=0.05$. For the 2 response variables (weight loss at 6 and 12 weeks categorical), multivariate models were conducted using the stepwise procedure with backward elimination and a lowest Bayesian information criterion (BIC) as a selection tool. The selection of variables used in the multivariate analyses was based on the significant variables from the earlier bivariate analyses, and stepwise procedures were done in consecutive steps. In step 1, the 7 continuous variables that affected weight loss at 12 weeks on a categorical scale were analyzed. In step 2, a similar stepwise approach was used with 11 categorical variables. For step 3, a narrower pool of candidate variables from both continuous and categorical models (steps 1 and 2) were used in a final model in a stepwise analysis. Similarly, the categorical weight loss at 6 weeks was analyzed starting with 3 independent continuous and 9 categorical variables from the bivariate fits. Parameter estimates (intercept and slopes with corresponding p-values), odds ratios, and 95\% confidence intervals were reported for the specific change of regressor variable or specific levels of categorical variables. In addition, the percent weight loss at 6 and 12 weeks as response variables on a continuous scale were analyzed. The details of analytical methods and results are in Appendix (A). 


\section{CHAPTER 4: RESULTS}

\section{Participant Characteristics}

Table 1 shows the baseline characteristics of participants who completed the telenutrition weight loss intervention program $(n=56)$ by group: the weight loss group (lost $\geq 5 \%$ of baseline weight) or the weight stable group (lost $<5 \%$ of baseline weight or gained weight) at 12 weeks. There were 31 participants $(55.4 \%)$ in the weight loss group and $25(44.6 \%)$ in the weight stable group.

The average age of the participants was $59.7 \pm 7.4$ years. A large majority were nonHispanic whites (91.1\%). All participants had at least a high school education, and more than 50\% had income levels $\geq \$ 75,000$. Most were diagnosed with hyperlipidemia (91.1\%) and hypertension (82.1\%), and the majority (64.3\%) were classified sedentary for physical activity. For the baseline weight and diet characteristics, the average BMI was $36.6 \pm 5.7 \mathrm{~kg} / \mathrm{m}^{2}$.

\begin{tabular}{|c|c|c|c|}
\hline & $\begin{array}{c}\text { All } \\
(\mathrm{n}=56)\end{array}$ & $\begin{array}{l}<5 \% \text { Weight } \\
\operatorname{Loss}^{1}(n=25)\end{array}$ & $\begin{array}{l}\geq 5 \% \text { Weight } \\
\operatorname{loss}^{1}(n=31)\end{array}$ \\
\hline & \multicolumn{3}{|c|}{ Mean \pm SD or $\mathrm{n}(\%)$} \\
\hline \multicolumn{4}{|l|}{ Demographic } \\
\hline Age, years & $59.7 \pm 7.4$ & $59.8 \pm 7.9$ & $59.6 \pm 7.1$ \\
\hline \multicolumn{4}{|l|}{ Age groups } \\
\hline$<65$ years & $37(67.3)$ & $16(64.0)$ & $21(70.0)$ \\
\hline$\geq 65$ years & $18(32.7)$ & $9(36.0)$ & $9(30.0)$ \\
\hline \multicolumn{4}{|l|}{ Ethnicity/Race } \\
\hline Non-Hispanic white & $51(91.07)$ & $21(84.0)$ & $30(96.8)$ \\
\hline Others & $5(8.9)$ & $4(16.0)$ & $1(3.2)$ \\
\hline \multicolumn{4}{|l|}{ Education } \\
\hline High school graduate & $13(23.2)$ & $4(16.0)$ & $9(29.0)$ \\
\hline Some college or technical school & $14(25)$ & $6(24.0)$ & $8(25.8)$ \\
\hline College graduate & $29(51.8)$ & $15(60)$ & $14(45.2)$ \\
\hline \multicolumn{4}{|l|}{ Work status $^{2}$} \\
\hline Employed & $37(66.1)$ & $18(72.0)$ & $19(61.3)$ \\
\hline Not employed & $19(33.9)$ & $7(28.0)$ & $12(38.7)$ \\
\hline \multicolumn{4}{|l|}{ Income } \\
\hline$\$ 20,000$ and $\$ 49,999$ & $11(22.0)$ & $5(23.8)$ & $6(20.7)$ \\
\hline$\$ 50,000$ and $\$ 74,999$ & $11(22.0)$ & $4(19.0)$ & $7(24.1)$ \\
\hline$\$ 75,000$ or more & $28(56.0)$ & $12(57.1)$ & $16(55.2)$ \\
\hline
\end{tabular}




\begin{tabular}{|c|c|c|c|}
\hline Health-Related Conditions & & & \\
\hline \multicolumn{4}{|l|}{ Smoking status } \\
\hline Current smoker & $24(46.2)$ & $10(41.7)$ & $14(50.0)$ \\
\hline Former/ Never smoker & $28(53.8)$ & $14(58.3)$ & $14(50.0)$ \\
\hline \multicolumn{4}{|l|}{ Comorbidities } \\
\hline Hyperlipidemia & $51(91.1)$ & $23(92.0)$ & $28(90.3)$ \\
\hline Hypertension & $46(82.1)$ & $22(88.0)$ & $24(77.4)$ \\
\hline \multicolumn{4}{|l|}{ Diabetes status } \\
\hline Diabetes & $12(21.4)$ & $8(32.0)$ & $4(12.9)$ \\
\hline Pre-diabetes & $17(30.4)$ & $8(32.0)$ & $9(29.0)$ \\
\hline None & $27(48.2)$ & $9(36.0)$ & $18(58.0)$ \\
\hline \multicolumn{4}{|l|}{ Number of comorbidities } \\
\hline 1 & $10(17.9)$ & $2(8.0)$ & $8(25.8)$ \\
\hline 2 & $22(39.3)$ & $10(40.0)$ & $12(38.7)$ \\
\hline 3 & $24(42.9)$ & $13(52.0)$ & $11(35.5)$ \\
\hline \multicolumn{4}{|l|}{ Self-rated health } \\
\hline Excellent / Very Good & $9(16.4)$ & $6(25.0)$ & $3(9.7)$ \\
\hline Good & $22(40.0)$ & $6(25.0)$ & $16(51.6)$ \\
\hline Fair/Poor & $24(43.6)$ & $12(50.0)$ & $12(38.7)$ \\
\hline \multicolumn{4}{|l|}{ Physical activity } \\
\hline Sedentary & $36(64.3)$ & $14(56.0)$ & $22(71.0)$ \\
\hline Active & $20(35.7)$ & $11(44.0)$ & $9(29.0)$ \\
\hline \multicolumn{4}{|l|}{ Weight/Diet Characteristics } \\
\hline $\mathrm{BMI}, \mathrm{kg} / \mathrm{m}^{2}$ & $36.6 \pm 5.7$ & $36.2 \pm 4.2$ & $36.9 \pm 6.8$ \\
\hline \multicolumn{4}{|l|}{ BMI classification } \\
\hline Obesity class I (BMI 30.0-34.9) & $22(39.3)$ & $8(32.0)$ & $14(45.2)$ \\
\hline Obesity class II (BMI 35-39.9) & $25(44.6)$ & $14(56.0)$ & $11(35.5)$ \\
\hline Obesity class III $(\mathrm{BMI} \geq 40)$ & $9(16.1)$ & $3(12.0)$ & $6(19.4)$ \\
\hline Baseline FFMI & $22.3 \pm 2.5$ & $22.1 \pm 2.2$ & $22.4 \pm 2.6$ \\
\hline \multicolumn{4}{|l|}{ Weight history, maintained weight ${ }^{3}$} \\
\hline$\leq 1$ year & $36(64.3)$ & $23(92.0)$ & $13(41.9)$ \\
\hline$\geq 2$ years & $20(35.7)$ & $2(8.0)$ & $18(58.1)$ \\
\hline Previously attempted weight loss, \% no & $29(51.8)$ & $9(36.0)$ & $20(64.5)$ \\
\hline Diet quality, HEI scores, 0-100 & $51.5 \pm 12.8$ & $55 \pm 13.8$ & $48.6 \pm 11.4$ \\
\hline \multicolumn{4}{|l|}{ Meals eaten in a restaurant/week } \\
\hline None or rare ${ }^{4}$ & $9(16.1)$ & $2(8.0)$ & $7(22.6)$ \\
\hline 1-2 times & $24(42.9)$ & $8(32.0)$ & $16(51.6)$ \\
\hline 3-5 times & $17(30.4)$ & $10(40.0)$ & $7(22.6)$ \\
\hline$\geq 6$ times & $6(10.7)$ & $5(20.0)$ & $1(3.2)$ \\
\hline
\end{tabular}

Abbreviations: Body Mass Index (BMI); Fat Free Mass Index (FFMI); Healthy Eating Index Scores (HEI). ${ }^{1}$ Weight loss defined as $\geq 5 \%$ loss of baseline weight; weight stable defined as $<$ $5 \%$ loss of baseline weight or gain weight. ${ }^{2}$ Employed (full-time + part-time + Self-employed), not employed (Retired + Unable to work). ${ }^{3} \leq 1$ year $(<6$ months +6 months to 1 year +1 year), $\geq 2$ years ( $2-4$ years $+>4$ years). ${ }^{4}$ Rare ( 1 every few weeks).

\section{Intervention Components Characteristics}

Table 2 shows the intervention component characteristics of participants who completed the telenutrition weight loss intervention program $(n=56)$ by weight loss group. Overall, the weight lost during the first 6 weeks was $3.3 \pm 2.8 \mathrm{~kg}$. Fifty percent of the participants always self- 
monitored their weekly weight, $28.6 \%$ used the meal planner more than $50 \%$ of the time, and $32.7 \%$ used the fruit/vegetable tracker more than $50 \%$ of the time. Also, most of the participants agreed that they were confident that they were adhering to the recommendations in the Playbook (43.6\%), knew what changes they needed to make to lose weight/eat more healthfully (87.5\%), and able to make the necessary changes to eat healthier and lose weight $(66.1 \%)$.

\begin{tabular}{|c|c|c|c|}
\hline & $\begin{array}{c}\text { All } \\
(n=56)\end{array}$ & $\begin{array}{l}<5 \% \text { Weight } \\
\text { Loss }^{1}(\mathrm{n}=25)\end{array}$ & $\begin{array}{l}\geq 5 \% \text { Weight } \\
\operatorname{loss}^{1}(n=31)\end{array}$ \\
\hline & \multicolumn{3}{|c|}{ Mean \pm SD or $n(\%)$} \\
\hline \multicolumn{4}{|l|}{ Weight/Body Composition } \\
\hline Weight loss, $\%$ weight loss at 6 weeks & $3.3 \pm 2.8$ & $1.2 \pm 1.6$ & $5.0 \pm 2.4$ \\
\hline FFMI at 6 weeks & $21.9 \pm 2.2$ & $21.9 \pm 2.3$ & $21.8 \pm 2.2$ \\
\hline \multicolumn{4}{|l|}{ Diet } \\
\hline Energy intake change at 6 weeks & $-465.6 \pm 512.5$ & $-291.7 \pm 524.0$ & $-605.8 \pm 465.3$ \\
\hline HEI change at 6 weeks & $14.0 \pm 16.9$ & $3.5 \pm 14.7$ & $22.4 \pm 13.7$ \\
\hline \multicolumn{4}{|l|}{ Strategies or Constructs } \\
\hline \multicolumn{4}{|l|}{ Self-monitoring weekly weight ${ }^{2}$} \\
\hline Always & $28(50.0)$ & $7(28.0)$ & $21(67.7)$ \\
\hline Sometimes or never & $28(50.0)$ & $18(72.0)$ & $10(32.3)$ \\
\hline \multicolumn{4}{|l|}{ Self-monitoring diet, week 6} \\
\hline \multicolumn{4}{|l|}{ Using of meal planner ${ }^{3}$} \\
\hline 1-3 weeks & $40(71.4)$ & $22(88.0)$ & $18(58.1)$ \\
\hline 4-6 weeks & $16(28.6)$ & $3(12.0)$ & $13(41.9)$ \\
\hline \multicolumn{4}{|l|}{ Using of fruit/vegetable tracker 3} \\
\hline $1-3$ weeks & $37(67.3)$ & $20(80.0)$ & $17(56.7)$ \\
\hline 4-6 weeks & $18(32.7)$ & $5(20.0)$ & $13(43.3)$ \\
\hline \multicolumn{4}{|c|}{ Self-efficacy (confident that I ...), \% Agree } \\
\hline know what changes to make & $49(87.5)$ & $21(84.0)$ & $28(90.3)$ \\
\hline can make the necessary changes & $37(66.1)$ & $11(44.0)$ & $26(83.9)$ \\
\hline am adhering to Playbook & $24(43.6)$ & $5(20.8)$ & $19(61.3)$ \\
\hline \multicolumn{4}{|l|}{ Social support } \\
\hline \multicolumn{4}{|l|}{ Partner helps my efforts } \\
\hline Yes & $42(75.0)$ & $16(64.0)$ & $26(83.9)$ \\
\hline No & $14(25.0)$ & $9(64.0)$ & $5(16.1)$ \\
\hline \multicolumn{4}{|l|}{ Partner also follows program } \\
\hline Yes & $24(42.9)$ & $7(28)$ & $17(54.8)$ \\
\hline No & $32(57.1)$ & $18(72.0)$ & $14(45.2)$ \\
\hline \multicolumn{4}{|l|}{ Partner lost weight $^{4}$} \\
\hline Agree & $17(30.4)$ & $4(16.0)$ & $13(41.9)$ \\
\hline Disagree or neutral & $39(69.6)$ & $21(84.0)$ & $18(41.9)$ \\
\hline \multicolumn{4}{|l|}{ Family started to eat better ${ }^{4}$} \\
\hline Agree & $19(34.5)$ & $5(20.8)$ & $14(45.2)$ \\
\hline
\end{tabular}




\begin{tabular}{|c|c|c|c|}
\hline Disagree or Neutral & $36(65.5)$ & $19(79.2)$ & $17(54.8)$ \\
\hline Conversations with my doctors 4,5 & & & \\
\hline Agree & $23(41.8)$ & $10(41.7)$ & $13(41.9)$ \\
\hline Disagree or Neutral & $32(58.2)$ & $14(58.3)$ & $18(58.1)$ \\
\hline Conversations with friends and family 4,5 & & & \\
\hline Agree & $15(27.3)$ & $13(54.2)$ & $27(87.1)$ \\
\hline Disagree or Neutral & $40(72.7)$ & $11(45.8)$ & $4(12.9)$ \\
\hline RDN Behavior Support & & & \\
\hline Received RDN behavioral support & & & $19(61.3)$ \\
\hline Intervention & $27(48.2)$ & $8(32.0)$ & $12(38.7)$ \\
\hline Control & $29(51.8)$ & $17(68.0)$ & 12 \\
\hline
\end{tabular}

Abbreviations: Fat-Free Mass Index (FFMI); Healthy Eating Index Scores (HEI); Registered Dietitian Nutritionist (RDN). ${ }^{1}$ Weight loss defined as $\geq 5 \%$ loss of baseline weight; weight stable defined as $<5 \%$ loss of baseline weight or gain weight. ${ }^{2}$ Self-monitoring weekly weight calculated from week 1-6 and 712 (Always means all 12 weeks' weights were monitored, sometimes means less than 12 weeks weights were recorded and never meant no weights were monitored). ${ }^{3}$ 1-3 weeks (Rarely or Never + Sometimes), 4-6 weeks (Always or Often). ${ }^{4}$ Agree (Agree or Strongly Agree), Disagree or Neutral (Strongly Disagree or Disagree + Neutral). ${ }^{5}$ (About weight-loss strategies I have learned in this program).

\section{RDN Behavioral Support}

Table 3 shows the frequency and the duration of MNT encounters and health coach call calls from an RDN behavior support for participants in the telenutrition intervention group only $(n=27)$. Overall, the average duration for the health coach call was about 15 minutes. The average time spent with an RDN was about 4 hours (231.1 \pm 60.1 minutes).

Table 3. RDN behavioral support for participants in the telenutrition intervention group $(\mathrm{n}=27)$

\begin{tabular}{|l|c|c|c|}
\hline & $\begin{array}{c}\text { All } \\
\mathrm{n}=27\end{array}$ & $\begin{array}{c}<5 \% \text { Weight loss }{ }^{1} \\
\mathrm{n}=8\end{array}$ & $\begin{array}{c}\geq 5 \% \text { Weight loss }{ }^{1} \\
\mathrm{n}=19\end{array}$ \\
\hline Health coach call frequency, number of calls & $8.2 \pm 1.4$ & $7.4 \pm 1.8$ & $8.6 \pm 1.0$ \\
\hline Average health coach call, total minutes & $15.0 \pm 4.8$ & $13.2 \pm 2.9$ & $15.7 \pm 5.2$ \\
\hline Time with an RDN (MNT + call), total minutes & $231.1 \pm 60.1$ & $203.6 \pm 34.5$ & $242.7 \pm 65.4$ \\
\hline$\%$ Of SMART goals met & $89.1 \pm 23.6$ & $76.6 \pm 34.8$ & $94.5 \pm 15.2$ \\
\hline
\end{tabular}

Abbreviations: Registered Dietitian Nutritionist (RDN); Medical Nutrition Therapy (MNT); SMART (Specific, Measurable, Attainable, Realistic, Time-bound). 1 Weight loss defined as $\geq 5 \%$ loss of baseline weight; weight stable defined as $<5 \%$ loss of baseline weight or gain weight.

\section{Effect of the Intervention on HEI and FFMI}

Matched pairs analysis examining the difference between the HEI changes recorded at 6 and 12 weeks from the baseline found there were no differences between 6 and 12 weeks. The mean difference $=1.72$, indicating that there was on average only a 1.72 points increase in HEI at 
12 weeks from the 6-week with respect to baseline, p-value= 0.3233). Figure 1 shows the matched pairs plot on HEI change at 6 and 12 weeks.

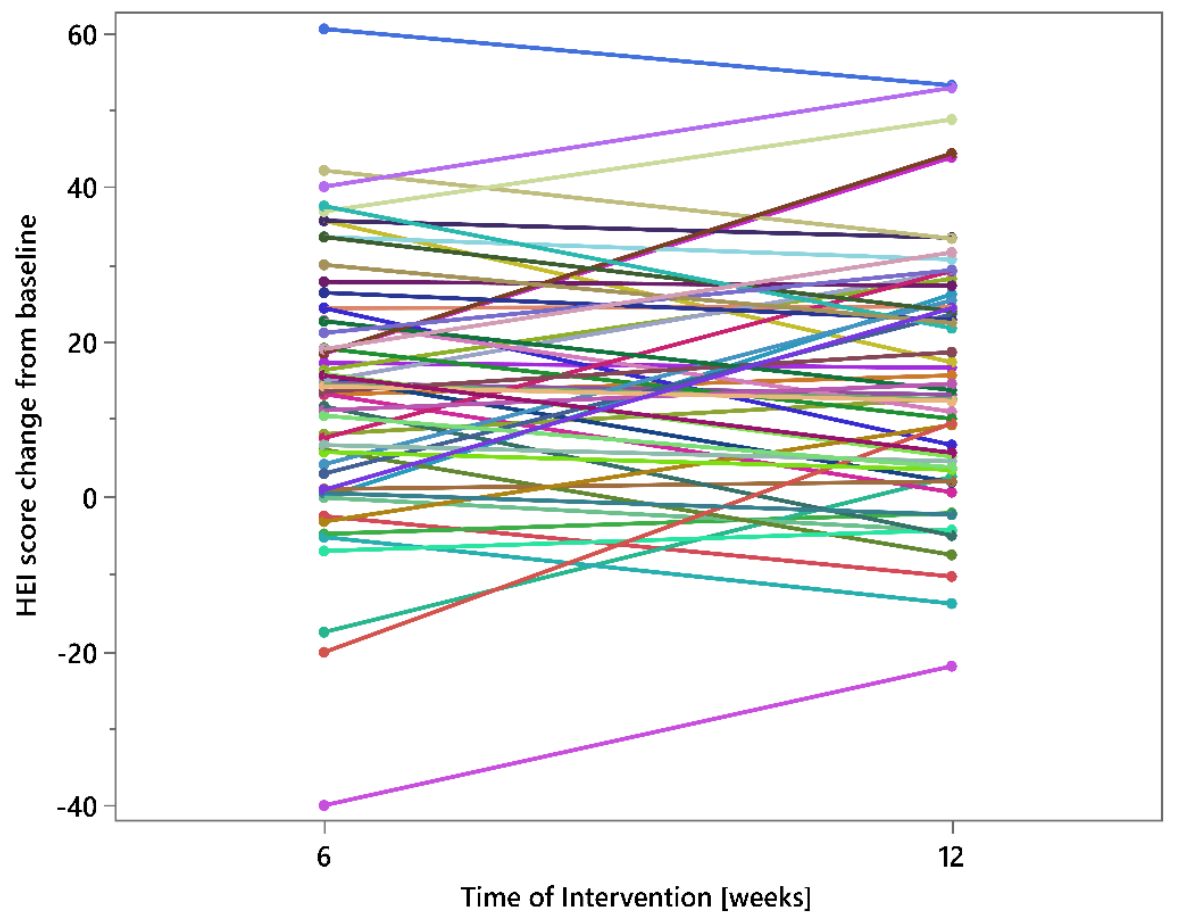

Figure 1. Matched pairs on HEI change at 6 and 12 weeks

Repeated measures ANOVA was performed to examine the effect of intervention time at 3time points (baseline, week 6, and week 12) on HEI and FFMI. There was a statistically significant effect of time of intervention on both HEI and FFMI ( $p<0.0001, p<0.0001$, respectively) (Figures 2 and 3). Specifically, HEI total scores increased significantly from 0 to 6 weeks $(\mathrm{p}<0.0001)$ as well as 0 to 12 weeks ( $\mathrm{p}<0.0001$ ), but there was no difference between 6 and 12 weeks. Similarly, FFMI scores decreased significantly from 0 to 6 weeks $(p=0.0002)$ as well as 0 to 12 weeks $(p<$ $0.0001)$, but there was no difference between 6 and 12 weeks. 


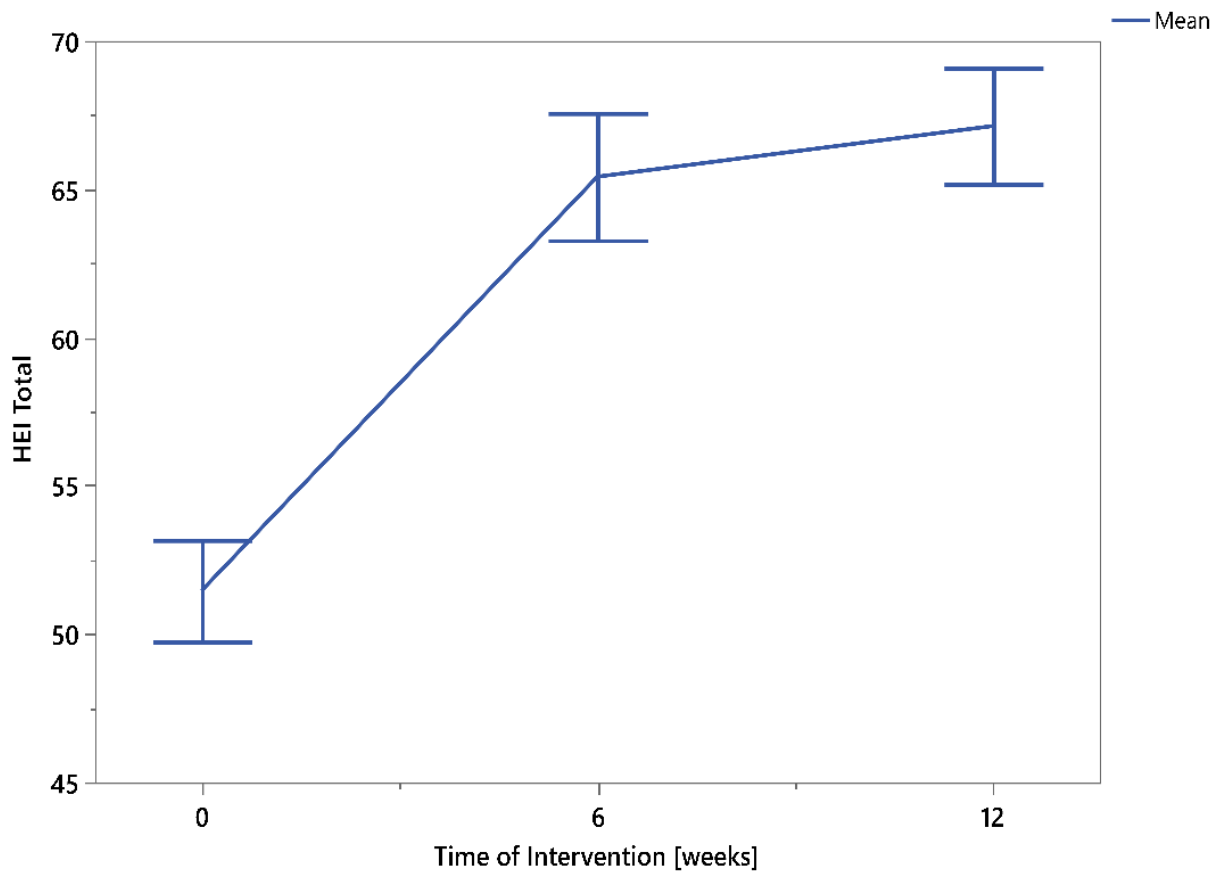

Figure 2. Repeated measures on total HEI score at 0, 6, and 12 weeks

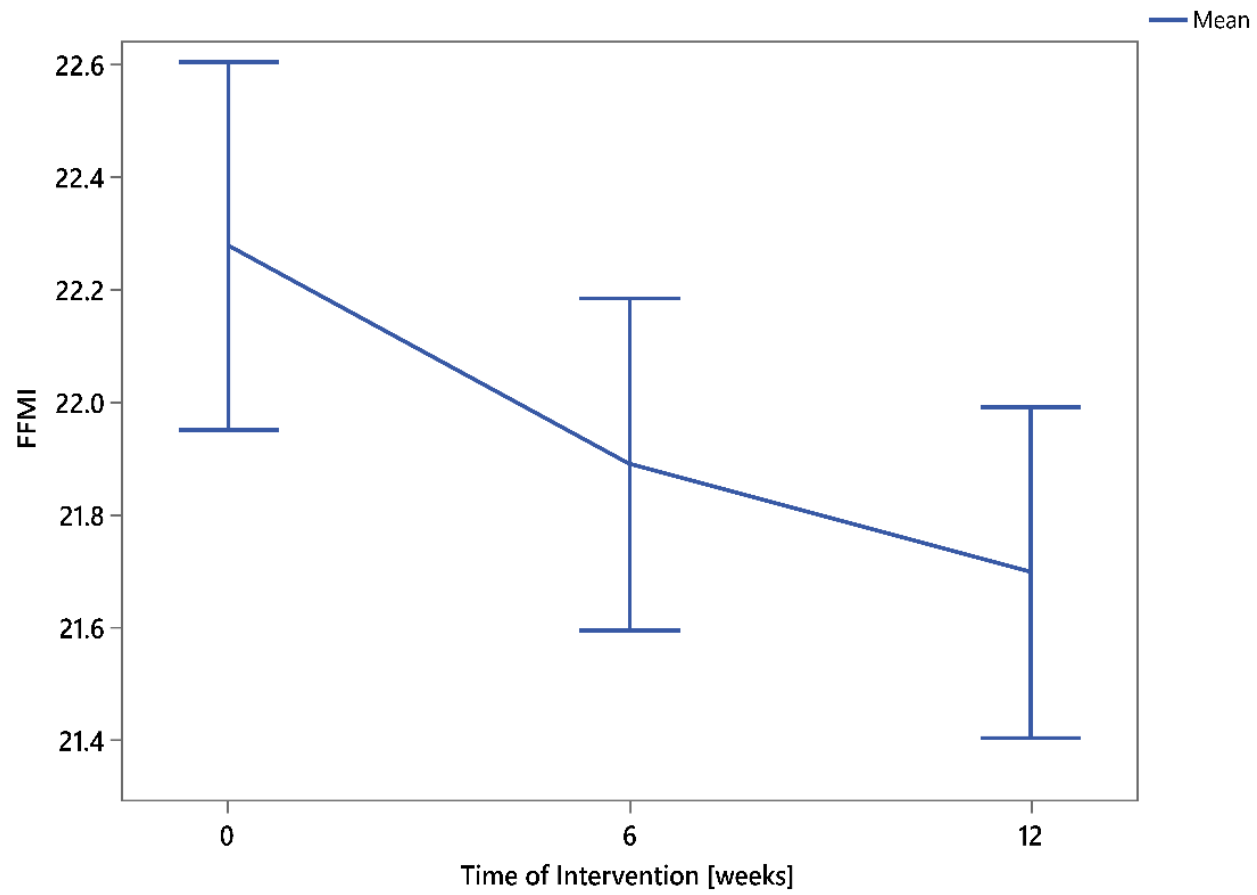

Figure 3. Repeated measures on FFMI at 0 , 6, and 12 weeks 


\section{Factors that Predict Weight Loss at 12 Weeks $(\geq 5 \%,<5 \%$ weight loss)}

Table 4 shows the effects of individual baseline characteristics, weight and body compositions factors, dietary factors, and intervention components (i.e., behavioral strategies, constructs, and RDN behavioral support) on the percentage of weight loss at 12 weeks (categorical variable). The odds of a favorable outcome, such as losing $\geq 5 \%$ of baseline weight versus not losing/gaining weight, are expressed in the form of odds ratio (OR) for indicated groups, or, in the case of continuous independent variables, in the form of odds ratio per a unit of the regressor. The length of time they maintained their baseline body weight (weight history), the number of meals eaten in a restaurant/week, and previous weight loss attempts were significant baseline factors in predicting whether people lost weight at 12 weeks. For instance, the OR $15.9(0.95 \%$ CI 3.2-79.8) for the weight history indicates the odds of losing weight ( $\geq 5 \%$ of baseline weight) for those who maintained their current body weight for at least 2 years are 15.9 times higher than the odds of losing weight for those who maintained their starting weight for only 1 year or less. Of the weight and body composition factors, the percentage of weight loss changes at 6 weeks affected weight loss of $\geq 5 \%$ of baseline weight. The corresponding OR 3.02 (Table 4 ) indicates that for every one percent increase in weight loss at 6 weeks, the odds of losing weight at 12 weeks are 3 -times higher than without the 1 percent increase at 6 weeks. In other words, a person with 1 percent increase in weight loss at 6 weeks, relative to others, is about 3-times more likely to lose weight at 12 weeks than without a 1 percent incremental increase at 6 weeks. Among the dietary factors, changes in caloric and HEI scores at 6 weeks affected weight loss at 12 weeks. Furthermore, the significant strategies in predicting whether people lose weight at 12 weeks included using the weekly meal planner, using self-monitoring weekly weight, confidence in the ability to make necessary changes to eat healthier and lose weight, confidence in adhering to recommendations in the Playbook, 
partner following the program, partner losing weight, and having conversations with friends, coworkers, or relatives about weight loss strategies they learned. In addition, being in the telenutrition intervention group, the number of health coach calls, average total minutes of health coach calls, total minutes with an RDN, and the percentage of different goals met were all essential predictors of whether participants lost $\geq 5 \%$ of their weight.

\begin{tabular}{|c|c|c|c|}
\hline & \multicolumn{3}{|c|}{ Odds of $\geq 5 \% /<5 \%$ Weight loss at week $12^{1}$} \\
\hline & Level & OR & $95 \% \mathrm{CI}$ \\
\hline \multicolumn{4}{|l|}{ Baseline characteristics } \\
\hline Diabetes status & \multicolumn{3}{|l|}{ NS } \\
\hline Weight history, maintained weight & $\geq 2$ years $/ \leq 1$ year $^{2}$ & 15.9 & $3.2-79.8^{* * * *}$ \\
\hline Meals eaten in a restaurant/week & None or rare $/ \geq 6$ times $^{3}$ & 17.5 & $1.2-250.3^{*}$ \\
\hline Previous weight loss attempts & $\mathrm{No} / \mathrm{Yes}^{4}$ & 3.2 & $1.1-9.7^{*}$ \\
\hline \multicolumn{4}{|l|}{ Weight/Body Composition } \\
\hline Weight loss at 6 weeks & per one unit of regressor & 3.02 & $1.7-5.5^{* * *}$ \\
\hline FFMI at 6 weeks & \multicolumn{3}{|l|}{ NS } \\
\hline \multicolumn{4}{|l|}{ Diet } \\
\hline Energy intake change at 6 weeks & per one unit of regressor & 0.99 & $0.997-0.999^{*}$ \\
\hline HEI change at 6 weeks & per one unit of regressor & 1.12 & $1.1-1.2^{* * * *}$ \\
\hline \multicolumn{4}{|l|}{ Strategies or Constructs } \\
\hline \multicolumn{4}{|l|}{ Self-monitoring diet } \\
\hline Using of meal planner & 4-6 weeks / 1-3 weeks ${ }^{5}$ & 5.3 & $1.3-21.5^{*}$ \\
\hline Using of Fruit and vegetable tracker & \multicolumn{3}{|l|}{$\mathrm{NS}$} \\
\hline Self-monitoring weekly Weight & Always / Sometimes or Never & 5.4 & $1.7-17.1^{* *}$ \\
\hline \multicolumn{4}{|l|}{ Self-efficacy (confident that I ...) } \\
\hline know what changes to make & \multicolumn{3}{|l|}{ NS } \\
\hline can make the necessary changes & Agree / Disagree or Neutral & 6.6 & $1.9-22.9^{*}$ \\
\hline am adhering to Playbook & Agree / Disagree or Neutral & 6.0 & $1.8-20.4^{* *}$ \\
\hline \multicolumn{4}{|l|}{ Social support } \\
\hline Partner helps my efforts & \multicolumn{3}{|l|}{ NS } \\
\hline Partner also follows program & Yes / No & 3.1 & $1.01-9.6^{*}$ \\
\hline Partner lost weight & Agree /Disagree or Neutral $^{6}$ & 3.8 & $1.04-13.7^{*}$ \\
\hline Family started to eat better & \multicolumn{3}{|l|}{ NS } \\
\hline Conversations with my doctors & \multicolumn{3}{|l|}{ NS } \\
\hline Conversations with friends and family & Agree / Disagree or Neutral ${ }^{6}$ & 5.7 & $1.5-21.4^{* *}$ \\
\hline \multicolumn{4}{|l|}{ RDN Behavior Support } \\
\hline Received an RDN behavioral support & Intervention / Control group & 3.4 & $1.1-10.2^{*}$ \\
\hline Health coach call frequency & per one unit of regressor & 1.18 & $1.03-1.4^{*}$ \\
\hline Average duration of health coach call & per one unit of regressor & 1.09 & $1.0-1.2^{*}$ \\
\hline Time with an RDN (MNT + Health coach call) & per one unit of regressor & 1.006 & $1.001-1.01^{*}$ \\
\hline$\%$ Of different SMART goals met & per one unit of regressor & 1.02 & $1.003-1.03^{*}$ \\
\hline
\end{tabular}

Abbreviations: Fat-Free Mass Index (FFMI); Healthy Eating Index Scores (HEI); Registered Dietitian Nutritionist (RDN); Medical Nutrition Therapy (MNT); SMART (Specific, Measurable, Attainable, Realistic, Time-bound); Not Significant (NS). 1 When the response variable (Weight loss at 12 weeks) is categorical (2 levels, lost $5 \%$ or 
did not), the analysis was determined by the type of the independent variable: In case of the continuous independent variable (weight loss \% change at 6 weeks, HEI change at 6 weeks, behavioral support from dietitian), logistic regression was used. In the case of categorical independent variables (nominal and ordinal), nominal logistic regression was used utilizing the likelihood ratio test. ${ }^{*} p<0.05 ; *$ p $<0.01 ; * * * p<0.00 .2 \leq 1$ year ( $<6$ months +6 months to 1 year +1 year), $\geq 2$ years $(2-4$ years $+>4$ years). 3 Rare ( 1 every few weeks). 4 No (none), Yes (choose any program from the choices) 5 1-3 weeks (Rarely or Never + Sometimes), 4-6 weeks (Always or Often). 6 Agree (Agree or Strongly Agree), Disagree or Neutral (Strongly Disagree or Disagree + Neutral).

\section{Final Predictors Factors for Weight Loss at 12 Weeks $(\geq 5 \%,<5 \%$ weight loss)}

Variables significant in the bivariate analysis (from Table 4) were entered into the first selection round in multivariate backward elimination. Significant variables from the first round (Model 1 and Model 2, Table 5) were: percent weight loss change at 6 weeks (continuous), how often one used weekly meal planner, conversations with friends, co-workers, or relatives, selfmonitoring weekly weight, and previous weight loss attempts (categorical). These variables were entered into the second selection round in multivariate backward elimination. The final predictive model for categorical weight loss at 12 weeks $(\geq 5 \%,<5 \%$ weight loss $)$ is shown in Table 5 .

The significant predictors were percent weight loss change at 6 weeks, weekly weight selfmonitoring, and previous weight loss attempts. Specifically, the odds ratio indicated that for every $1 \%$ increase in percent weight loss change at 6 weeks, the probability that a person had a weight loss of $\geq 5 \%$ at 12 weeks from baseline increased 5.04 times. Also, the odds of losing weight $(\geq$ $5 \%$ ) if the person always used the self-monitoring weekly weight were 33.53 times higher than the odds of losing weight if the person never or sometimes self-monitored weekly weight. Moreover, the odds of losing weight if the person did not use any program to lose weight in the past were 63.82 times higher than the odds of losing weight if the person was using any other program.

In summary, the final model indicated that participants who had achieved $\geq 5 \%$ weight loss at 12-weeks had lost more weight at 6 weeks, had not previously attempted weight loss, and always self-monitored their weekly weight. 
An alternative predictive model for categorical weight loss at 12 weeks $(\geq 5 \%,<5 \%$ weight loss) was developed purposefully without using $\%$ weight loss change at 6 weeks, as that could be considered an intermediary success or response. This group of intermediary and final alternative models is reported in Table 6 . The significant predictors were HEI change score at 6 weeks, selfmonitoring weekly weight, how often one used the weekly meal planner, and previous weight loss attempt. In particular, the odds ratio indicated that for every 1 score increase in HEI change score at 6 weeks, the probability that a person lost $\geq 5 \%$ of weight at 12 weeks from baseline increased 1.15 times. Also, the odds of losing weight $(\geq 5 \%)$ if the person used the weekly meal planner for 4-6 weeks were 8.39 times higher than the odds of losing weight if the person used the weekly meal planner for 1-3 weeks. The odds of losing weight $(\geq 5 \%)$ if the person always used the selfmonitoring weekly weight were 10.03 times higher than the odds of losing weight if the person never or sometimes used the self-monitoring weekly weight. Additionally, the odds of losing weight if the person did not use any program to lose weight in the past were 17.93 times higher than the odds of losing weight if the person was using any other program.

In summary, the final alternative model indicated that participants who had achieved $\geq 5 \%$ weight loss at 12-weeks had: higher HEI changes scores at 6 weeks, no previous weight loss attempts, always self-monitored weekly weight, and used the weekly meal planner more often. 


\begin{tabular}{|c|c|c|c|c|c|c|c|}
\hline \multicolumn{8}{|c|}{ Model 1. Effect of independent continuous variables onto $\geq 5 \% /<5 \%$ weight loss at 12 weeks (Categorical) } \\
\hline & Estimate & $\begin{array}{c}\text { Std } \\
\text { Error }\end{array}$ & $\begin{array}{c}\text { Chi } \\
\text { Square }\end{array}$ & $\begin{array}{c}\mathrm{p}- \\
\text { value }\end{array}$ & Level & OR & $95 \% \mathrm{CI}$ \\
\hline Intercept & -2.76 & 0.80 & 11.77 & 0.0006 & & & \\
\hline Percent weight loss change at 6 weeks & 1.10 & 0.30 & 13.54 & 0.0002 & per one unit of regressor & 3.026 & $1.7-5.5$ \\
\hline \multicolumn{8}{|c|}{ Model 2. Effect of independent categorical variables onto $\geq 5 \%$ / $<5 \%$ weight loss at 12 weeks (Categorical) } \\
\hline & Estimate & $\begin{array}{l}\text { Std } \\
\text { Error }\end{array}$ & $\begin{array}{c}\text { Chi } \\
\text { Square }\end{array}$ & $\begin{array}{c}\mathrm{p}- \\
\text { value }\end{array}$ & Level & OR & $95 \% \mathrm{CI}$ \\
\hline Intercept & 0.48 & 0.46 & 1.09 & 0.2969 & & & \\
\hline Often used weekly meal planner (1-3 weeks) ${ }^{2}$ & -1.31 & 0.52 & 6.31 & 0.0120 & 4-6weeks / 1-3weeks ${ }^{2}$ & 13.92 & $1.8-108.8$ \\
\hline $\begin{array}{l}\text { Conversations with friends, co-workers, or relatives (Disagree } \\
\text { or Neutral) }{ }^{3}\end{array}$ & -1.54 & 0.52 & 8.74 & 0.0031 & Agree / Disagree or neutral ${ }^{3}$ & 21.83 & $2.8-168.7$ \\
\hline Self-monitoring weekly weight (Always) & 1.46 & 0.49 & 8.68 & 0032 & Always/Sometimes or & 18.80 & $2.7-132.5$ \\
\hline Previous weight loss attempts (No) ${ }^{4}$ & 1.22 & 0.47 & 6.62 & 0.0101 & $\mathrm{No} / \mathrm{Yes}^{4}$ & 11.56 & $1.8-74.7$ \\
\hline \multicolumn{8}{|c|}{ Final model. Effect of independent continuous and categorical variables onto $\geq 5 \% /<5 \%$ weight loss at 12 weeks (Categorical) } \\
\hline & Estimate & $\begin{array}{c}\text { Std } \\
\text { Error }\end{array}$ & $\begin{array}{c}\text { Chi } \\
\text { Square }\end{array}$ & $\begin{array}{c}\mathrm{p}- \\
\text { value }\end{array}$ & Level & OR & $95 \% \mathrm{CI}$ \\
\hline Intercept & -3.68 & 1.34 & 7.52 & 0.0061 & & & \\
\hline Self-monitoring weekly weight (Always) & 1.75 & 0.79 & 4.92 & 0.0266 & Always / Sometimes or Never & 33.53 & $1.5-748.2$ \\
\hline Previous weight loss attempt (No) ${ }^{4}$ & 2.07 & 0.87 & 5.70 & 0.0170 & $\mathrm{No} / \mathrm{Yes}^{4}$ & 63.82 & $2.1-1938.1$ \\
\hline Percent weight loss change at 6 weeks & 1.61 & 0.55 & 8.56 & 0.0034 & per one unit of regressor & 5.04 & $1.7-14.9$ \\
\hline \multicolumn{8}{|c|}{$\begin{array}{l}{ }^{1} \text { Multivariate model were determined using the stepwise procedure with backward elimination using the lowest Bayesian information criterion (BIC) as a selection } \\
\text { tool. The selection of variables used in multivariate analyses was based on the significant variables from the earlier bivariate analyses, and stepwise procedures were } \\
\text { done in consecutive steps. Model the categorical response (lost } 5 \% \text { or more of the baseline weight or not), stepwise logistic regression and nominal logistic regressions } \\
\text { were employed, with continuous (7) and categorical (11) independent variables, respectively. A final model was developed from the intermediary models, using the } \\
\text { BIC criteria [previous weight loss attempts, frequency of use the meal planner, self-monitoring weekly weight, and conversation with friends and family are } \\
\text { categorical (nominal) variables and reference groups are listed in parentheses for parameter estimates]. }{ }^{2} 1-3 \text { weeks (Rarely or Never + Sometimes), } 4-6 \text { weeks } \\
\text { (Always or Often). }{ }^{3} \text { Agree (Agree or Strongly Agree), Disagree or Neutral (Strongly Disagree or Disagree + Neutral) }{ }^{4} \text { No (none), Yes (choose any program from } \\
\text { the choices). }\end{array}$} \\
\hline
\end{tabular}




\begin{tabular}{|c|c|c|c|c|c|c|c|}
\hline \multicolumn{8}{|c|}{ Model 1. Effect of independent continuous variables onto $\geq 5 \% /<5 \%$ weight loss at 12 weeks (Categorical) } \\
\hline & Estimate & $\begin{array}{c}\text { Std } \\
\text { Error }\end{array}$ & $\begin{array}{c}\text { Chi } \\
\text { Square }\end{array}$ & $\begin{array}{c}\mathrm{p}- \\
\text { value }\end{array}$ & Level & OR & $95 \% \mathrm{CI}$ \\
\hline Intercept & -1.33 & 0.54 & 6.00 & 0.0143 & & & \\
\hline HEI change score at 6 weeks & 0.11 & 0.03 & 11.93 & 0.0006 & per one unit of regressor & 1.12 & $1.1-1.2$ \\
\hline \multicolumn{8}{|c|}{ Model 2. Effect of independent categorical variables onto $\geq 5 \% /<5 \%$ weight loss at 12 weeks (Categorical) } \\
\hline & Estimate & $\begin{array}{l}\text { Std } \\
\text { Error }\end{array}$ & $\begin{array}{c}\text { Chi } \\
\text { Square }\end{array}$ & $\begin{array}{c}\text { p- } \\
\text { value }\end{array}$ & Level & OR & $95 \% \mathrm{CI}$ \\
\hline Intercept & 0.48 & 0.46 & 1.09 & 0.2969 & & & \\
\hline Often used weekly meal planner (1-3 weeks) ${ }^{2}$ & -1.31 & 0.52 & 6.31 & 0.0120 & 4-6weeks / 1-3weeks ${ }^{2}$ & 13.92 & $1.8-108.8$ \\
\hline $\begin{array}{l}\text { Conversations with friends, co-workers, or relatives (Disagree } \\
\text { or Neutral) }\end{array}$ & -1.54 & 0.52 & 8.74 & 0.0031 & Agree / Disagree or neutral ${ }^{3}$ & 21.83 & $2.8-168.7$ \\
\hline Self-monitoring weekly weight (Always) & 1.46 & 0.49 & 8.68 & 0.0032 & Always/ Sometimes or Never & 18.80 & $2.7-132.5$ \\
\hline Previous weight loss attempts (No) ${ }^{4}$ & 1.22 & 0.47 & 6.62 & 0.0101 & $\mathrm{No} / \mathrm{Yes}^{4}$ & 11.56 & $1.8-74.7$ \\
\hline \multicolumn{8}{|c|}{ Final alternative model. Effect of independent continuous and categorical variables onto $\geq 5 \% /<5 \%$ weight loss at 12 weeks $($ Categorical) } \\
\hline & Estimate & $\begin{array}{c}\text { Std } \\
\text { Error }\end{array}$ & $\begin{array}{c}\text { Chi } \\
\text { Square }\end{array}$ & $\begin{array}{c}\mathrm{p}- \\
\text { value }\end{array}$ & Level & OR & $95 \% \mathrm{CI}$ \\
\hline Intercept & -0.98 & 0.74 & 1.76 & 0.1842 & & & \\
\hline Self-monitoring weekly weight (Always) & 1.15 & 0.50 & 5.27 & 0.0217 & Always/Sometimes or Never & 10.03 & $1.4-71.8$ \\
\hline Previous weight loss attempt (No) ${ }^{4}$ & 1.44 & 0.53 & 7.27 & 0.0070 & $\mathrm{No} / \mathrm{Yes}^{4}$ & 17.93 & $2.2-146.3$ \\
\hline Often used weekly meal planner (1-3 weeks) ${ }^{2}$ & -1.06 & 0.56 & 3.56 & 0.0591 & 4-6weeks / 1-3weeks ${ }^{2}$ & 8.39 & $0.92-76.5$ \\
\hline HEI change score at 6 weeks & 0.14 & 0.04 & 9.75 & 0.0018 & per one unit of regressor & 1.15 & $1.1-1.3$ \\
\hline
\end{tabular}

Abbreviations: Healthy Eating Index Scores (HEI). ${ }^{1}$ Multivariate model were determined using the stepwise procedure with backward elimination using the lowest Bayesian information criterion (BIC) as a selection tool. The selection of variables used in multivariate analyses was based on the significant variables from the earlier bivariate analyses, and stepwise procedures were done in consecutive steps. Model the categorical response (lost $5 \%$ or more of the baseline weight or not), stepwise logistic regression and nominal logistic regressions were employed, with continuous (6) and categorical (11) independent variables, respectively. A final model was developed from the intermediary models, using the BIC criteria [previous weight loss attempts, frequency of use the meal planner, self-monitoring weekly weight, and conversation with friends and family are categorical (nominal) variables and reference groups are listed in parentheses for parameter estimates]. ${ }^{2} 1-3$ weeks (Rarely or Never +Sometimes), 4-6 weeks (Always or Often). ${ }^{3}$ Agree (Agree or Strongly Agree), Disagree or Neutral (Strongly Disagree or Disagree + Neutral). ${ }^{4}$ No (none), Yes (choose any program from the choices) 
Factors that Predict the Percentage of Weight Loss at 6 Weeks $\geq 3.5 \%,<3.5 \%$ weight

loss)

Since weight loss at 6 weeks was a strong predictor of weight loss at 12 weeks and to identify the cut point for early weight loss (6 weeks) to achieve and become successful at the 12 week, people who lost $\geq 3.5 \%$ of baseline weight 6 weeks were at least $75 \%$ likely to lose $\geq 5 \%$ of their weight at 12 weeks (Figure 4).

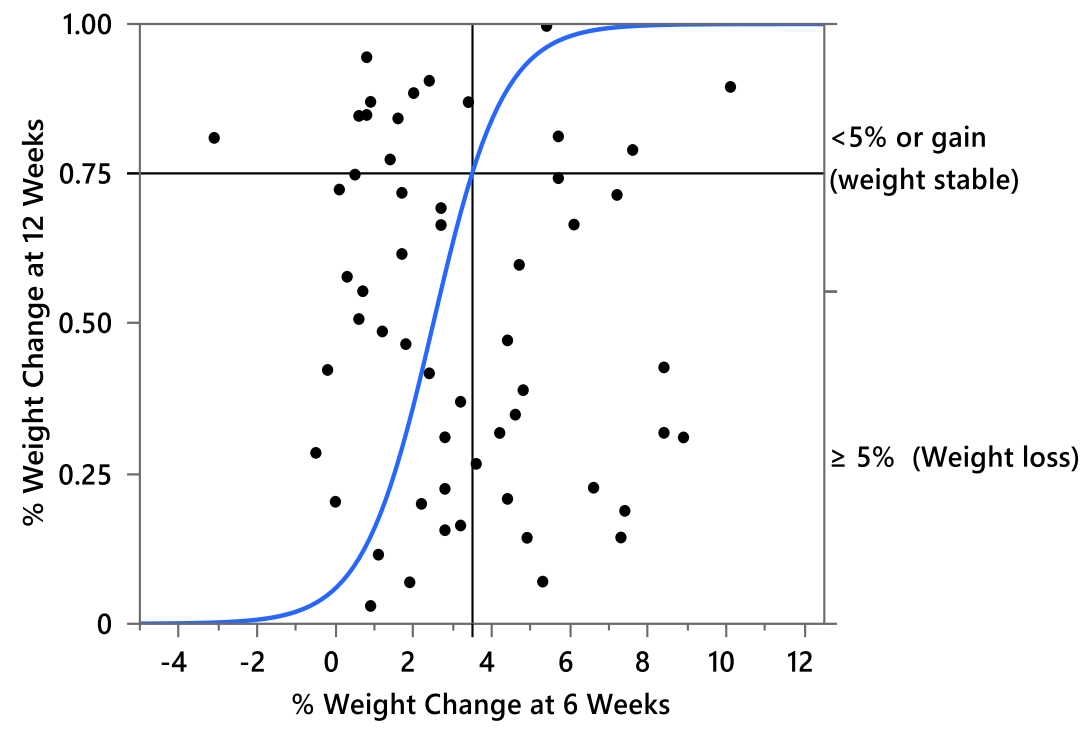

Figure 4. Prediction of percentage weight change at 6 weeks to lose $\geq 5 \%$ of baseline weight at 12 weeks

Effects of individual baseline characteristics on the percentage of weight loss at 6 weeks (categorical variable) are reported in Table 7. The baseline FFMI, diabetes status, number of comorbidities, the length of having their current body weight, and number of meals eaten in a restaurant/week were the 4 significant baseline factors in predicting whether people lose $\geq 3.5 \%$ weight or have a stable weight $<3.5 \%$ at 6 weeks.

Effects of the intervention components on the percentage of weight loss at 6 weeks (categorical variable) are listed in Table 8. Only changes in HEI scores at 6 weeks affected weight loss of $\geq 3.5 \%$ of the baseline weight from dietary factors. Furthermore, the significant strategies in predicting whether people lose $\geq 3.5 \%$ weight at 6 weeks included using the weekly meal 
planner, confidence in the ability to make necessary changes to eat healthier and lose weight, partner lost weight, agreeing on family eating better and conversations with friends, coworkers, or relatives about weight loss strategies they learned. The percentage of different goals met was only an RDN behavioral support factor predicting whether patients lost weight or not at 6 weeks.

\begin{tabular}{|c|c|c|c|}
\hline & Odds of $\geq 3.5 \% /<3.5 \%$ & ght lo & at week $6^{1}$ \\
\hline & Level & OR & $\mathrm{CI}$ \\
\hline Age & \multicolumn{3}{|c|}{ NS } \\
\hline Age groups & \multicolumn{3}{|c|}{ NS } \\
\hline Ethnicity/Race & \multicolumn{3}{|c|}{ NS } \\
\hline Education & \multicolumn{3}{|c|}{ NS } \\
\hline Work status & \multicolumn{3}{|c|}{ NS } \\
\hline Income & \multicolumn{3}{|c|}{ NS } \\
\hline Smoking status & \multicolumn{3}{|c|}{ NS } \\
\hline BMI & \multicolumn{3}{|c|}{ NS } \\
\hline BMI classification & \multicolumn{3}{|l|}{ NS } \\
\hline Baseline FFMI & per one unit of regressor & 1.33 & $1.02-1.7^{*}$ \\
\hline Baseline weight & \multicolumn{3}{|l|}{ NS } \\
\hline Comorbidities & & & \\
\hline Hypertension & \multicolumn{3}{|c|}{ NS } \\
\hline Hyperlipidemia & \multicolumn{3}{|c|}{ NS } \\
\hline Diabetes status & None / Diabetes & 6.2 & $1.1-34.1^{*}$ \\
\hline \multirow{2}{*}{ Number of comorbidities } & $1 / 3$ & 5.7 & $1.1-28.3^{*}$ \\
\hline & $2 / 3$ & 3.8 & $1.04-13.8^{*}$ \\
\hline Self-rated health & \multicolumn{3}{|c|}{ NS } \\
\hline Physical activity & \multicolumn{3}{|c|}{ NS } \\
\hline Weight history & $\geq 2$ years $/ \leq 1$ year $^{2}$ & 3.9 & $1.2-12.4^{*}$ \\
\hline Previously attempted weight loss & \multicolumn{3}{|l|}{$\mathrm{NS}$} \\
\hline Diet & & & \\
\hline Energy & \multicolumn{3}{|c|}{ NS } \\
\hline Diet quality (HEI) & \multicolumn{3}{|c|}{ NS } \\
\hline Number of meals eaten in a restaurant/week & 1-2 times / 3-5 times & 4.6 & $1.1-18.2^{* * *}$ \\
\hline
\end{tabular}

Abbreviations: Fat-Free Mass Index (FFMI); Body Mass Index (BMI); Healthy Eating Index Scores (HEI); Not Significant (NS). ${ }^{1}$ When the response variable (Weight loss at 6 weeks) was categorical (2 levels, lost $\geq 3.5 \%$ or $<3.5 \%$ ), the analysis is determined by the type of the independent variable: In case of the continuous independent variable (age, BMI, baseline FFMI, baseline weight, energy, HEI scores), logistic regression was used. In the case of categorical independent variables (nominal and ordinal), nominal logistic regression was used utilizing the likelihood ratio test. ${ }^{*} \mathrm{p}<0.05 ;{ }^{* *} \mathrm{p}<0.01 ;{ }^{* * *} \mathrm{p}<0.001$. $2 \leq 1$ year $(<6$ months +6 months to 1 year +1 year $), \geq 2$ years $(2-4$ years $+>4$ years $)$. 


\begin{tabular}{|c|c|c|c|}
\hline \multicolumn{4}{|c|}{$\begin{array}{l}\text { Table 8. Bivariate analysis of the percentage of weight loss at } 6 \text { weeks (Categorical) by Intervention } \\
\text { Component potentially affecting if a participant lost weight } \\
\text { Odds of } \geq 3.5 \% /<3.5 \% \text { Weight loss at week } 6^{1}\end{array}$} \\
\hline & Level & OR & $\mathrm{CI}$ \\
\hline \multicolumn{4}{|l|}{ Weight/ Body composition } \\
\hline FFMI at 6 weeks & \multicolumn{3}{|l|}{ NS } \\
\hline \multicolumn{4}{|l|}{ Diet } \\
\hline Change energy intake $0-6$ weeks & \multicolumn{3}{|l|}{ NS } \\
\hline HEI change at 6 weeks & per one unit of regressor & 1.1 & $1.0-1.1^{* *}$ \\
\hline \multicolumn{4}{|l|}{ Strategies or Constructs } \\
\hline Self-monitoring weekly weight ${ }^{2}$ & \multicolumn{3}{|l|}{ NS } \\
\hline \multicolumn{4}{|l|}{ Self-monitoring diet } \\
\hline Using of meal planner & 4-6 weeks / 1-3 weeks ${ }^{3}$ & 3.8 & $1.1-13.1^{*}$ \\
\hline Using of fruit and vegetable tracker & \multicolumn{3}{|l|}{ NS } \\
\hline \multicolumn{4}{|l|}{ Self-efficacy (confident that I ...) } \\
\hline know what changes to make & \multicolumn{3}{|l|}{ NS } \\
\hline can make the necessary changes & Agree/Neutral or Disagree & 3.6 & $1-12.7^{*}$ \\
\hline am adhering to Playbook & \multicolumn{3}{|l|}{$\mathrm{NS}$} \\
\hline \multicolumn{4}{|l|}{ Social support } \\
\hline Partner helps my efforts & \multicolumn{3}{|l|}{ NS } \\
\hline Partner also follows program & \multicolumn{3}{|l|}{ NS } \\
\hline Partner lost weight & Agree / Disagree or Neutral ${ }^{4}$ & 3.2 & $0.9-10.4^{*}$ \\
\hline Family started to eat better & Agree / Disagree or neutral ${ }^{4}$ & 4.5 & $1.4-14.6^{*}$ \\
\hline Conversations with my doctors & \multicolumn{3}{|l|}{ NS } \\
\hline Conversations with friends and family & Agree / Disagree or neutral ${ }^{4}$ & 15.5 & $1.9-129.1^{*}$ \\
\hline \multicolumn{4}{|l|}{ RDN Behavior Support $^{5}$} \\
\hline Received an RDN behavioral support & \multicolumn{3}{|l|}{ NS } \\
\hline Health coach call frequency & \multicolumn{3}{|l|}{ NS } \\
\hline Average health coach call & \multicolumn{3}{|l|}{ NS } \\
\hline Time with an RDN (MNT + Health coach call) & \multicolumn{3}{|l|}{ NS } \\
\hline$\%$ Of different SMART goals met & per one unit of regressor & 1.01 & $1.002-1.02^{*}$ \\
\hline
\end{tabular}

Abbreviations: Fat-Free Mass Index (FFMI); Healthy Eating Index Scores (HEI); Registered Dietitian Nutritionist (RDN); Medical Nutrition Therapy (MNT); SMART (Specific, Measurable, Attainable, Realistic, Time-bound); Not Significant (NS). 1 When the response variable (Weight loss at 12 weeks) is categorical (2 levels, lost 5\% or did not), the analysis is determined by the type of the independent variable: In case of the continuous independent variable (FFMI at 6 weeks, change energy intake 0- 6 weeks, HEI change at 6 weeks, behavioral support from dietitian), logistic regression is used. In the case of categorical independent variables (nominal and ordinal), nominal logistic regression was used utilizing the likelihood ratio test. $* \mathrm{p}<0.05 ; * \mathrm{p}<0.01$; *** $\mathrm{p}<0.001 .2$ Self-monitoring weekly weight (at 6 weeks) was used. 3 1-3 weeks (Rarely or Never + Sometimes), 4-6 weeks (Always or Often).4Agree (Agree or Strongly Agree), Disagree or Neutral (Strongly Disagree or Disagree + Neutral).5 Behavioral support from dietitian (at 6 weeks) were used.

Final Predictors Factors for Percentage of Weight Loss at 6 Weeks $(\geq 3.5 \%,<3.5 \%$ weight

loss)

Variables significant in bivariate analysis (from Table 7 and 8) were entered into the first selection round in multivariate backward elimination. Significant variables from the first round 
(Model 1 and Model 2, Table 9) were HEI change score at 6 weeks (continuous), conversations with friends, co-workers, or relatives, and family started to eat better (categorical). These variables were entered into the second selection round in multivariate backward elimination. The final predictive model for categorical weight loss at 6 weeks $(\geq 3.5 \%,<3.5 \%$ weight loss) is shown in Table 9. The final model indicated that participants who had achieved $\geq 3.5 \%$ weight loss at 6 weeks had a higher HEI change score at 6 weeks and agreed that the family started to eat better. 


\begin{tabular}{|c|c|c|c|c|c|c|c|}
\hline \multicolumn{8}{|c|}{ Model 1. Effect of independent continuous variables onto $\geq 3.5 \% /<3.5 \%$ weight loss at 6 weeks (Categorical) } \\
\hline & Estimate & $\begin{array}{c}\text { Std } \\
\text { Error }\end{array}$ & $\begin{array}{c}\text { Chi } \\
\text { Square }\end{array}$ & p-value & Level & OR & $95 \% \mathrm{CI}$ \\
\hline Intercept & -1.71 & 0.53 & 10.09 & 0.0015 & & & \\
\hline HEI change score at 6 weeks & 0.08 & 0.02 & 9.52 & 0.0020 & per one unit of regressor & 1.08 & $1.02-1.1$ \\
\hline \multicolumn{8}{|c|}{ Model 2. Effect of independent categorical variables onto $\geq 3.5 \% /<3.5 \%$ weight loss at 6 weeks $($ Categorical $)$} \\
\hline & Estimate & $\begin{array}{c}\text { Std } \\
\text { Error }\end{array}$ & $\begin{array}{c}\text { Chi } \\
\text { Square }\end{array}$ & p-value & Level & OR & $95 \% \mathrm{CI}$ \\
\hline Intercept & -0.97 & 0.56 & 3.01 & 0.0830 & & & \\
\hline $\begin{array}{l}\text { Conversations with friends, co-workers, or relatives } \\
\text { (Disagree or Neutral) }^{2}\end{array}$ & -1.27 & 0.55 & 5.37 & 0.0205 & Agree / Disagree or Neutral ${ }^{2}$ & 12.89 & $1.5-112.1$ \\
\hline Family started to eat better (Disagree or Neutral) ${ }^{2}$ & -0.68 & 0.33 & 4.13 & 0.0422 & Agree / Disagree or Neutral ${ }^{2}$ & 3.92 & 1.1-14.6 \\
\hline \multicolumn{8}{|c|}{ Final model. Effect of independent continuous and categorical variables onto $\geq 3.5 \% /<3.5 \%$ weight loss at 6 weeks $($ Categorical) } \\
\hline & Estimate & $\begin{array}{c}\text { Std } \\
\text { Error }\end{array}$ & $\begin{array}{c}\text { Chi } \\
\text { Square }\end{array}$ & p-value & Level & OR & $95 \% \mathrm{CI}$ \\
\hline Intercept & -1.55 & 0.58 & 7.00 & 0.0082 & & & \\
\hline HEI change score at 6 weeks & 0.08 & 0.02 & 8.69 & 0.0032 & per one unit of regressor & 1.08 & $1.02-1.1$ \\
\hline Family started to eat better (Disagree or Neutral) ${ }^{2}$ & -0.80 & 0.34 & 5.27 & 0.0217 & Agree / Disagree or Neutral $^{2}$ & 4.96 & $1.3-19.5$ \\
\hline
\end{tabular}

Abbreviations: Healthy Eating Index Scores (HEI). ${ }^{1}$ Multivariate model were determined using the stepwise procedure with backward elimination using the lowest Bayesian information criterion (BIC) as a selection tool. The selection of variables used in multivariate analyses was based on the significant variables from the earlier bivariate analyses, and stepwise procedures were done in consecutive steps. Model the categorical response (lost $3.5 \%$ or more of the baseline weight or not), stepwise logistic regression, and nominal logistic regressions were employed, with continuous (3) and categorical (9) independent variables, respectively. A final model was developed from the intermediary models, using the BIC criteria [Family started to eat better, and conversation with friends and family are categorical (nominal) variables and reference groups are listed in parentheses for parameter estimates]. ${ }^{2}$ Agree (Agree or Strongly Agree), Disagree or Neutral (Strongly Disagree or Disagree + Neutral). 


\section{CHAPTER 5: DISCUSSION}

The purpose of this study is to determine baseline and intervention factors associated with clinically significant weight loss ( $\geq 5 \%$ of baseline weight) among middle-aged and older men participating in a 12-week telenutrition weight loss intervention in $\mathrm{WV}$. The results indicate that early weight loss (weight loss during the first 6 weeks) was a strong predictor of $\geq 5 \%$ weight loss at 12 weeks, in addition to previous weight loss attempts and weekly self- monitoring of body weight $(p<0.05)$. If participants lost $\geq 3.5 \%$ of their initial weight at 6 weeks, their chances of losing at least $5 \%$ of body weight at 12 weeks were $\geq 75 \%$. An increase in diet quality scores at 6 weeks and agreed that receiving social support from other family members and starting to eat better were two main factors related to early weight loss at 6 weeks.

Final Predictors Factors for Weight Loss at 12 Weeks ( $\geq 5 \%,<5 \%$ weight loss)

In this study, $55.4 \%$ of participants lost $\geq 5 \%$ of baseline body weight, and $44.6 \%$ lost $<$ $5 \%$ of baseline body weight at 12 weeks.-Early weight loss at 6 weeks was a strong predictor of weight loss success at 12 weeks. The odds ratio indicated that for every $1 \%$ increase in the percentage of weight loss change at 6 weeks, the probability that a person lost weight of $\geq 5 \%$ at 12 weeks increased by approximately 5.04 times. This finding is comparable to the results of 2 studies from the Look AHEAD trial among middle-aged and older obese adults with type 2 diabetes in 2014 and 2015. ${ }^{64,65}$ In the 2014 study, weight loss at 1 and 2 months was predictive of 1-year weight loss. ${ }^{76}$ Additionally, a 2015 trial found that weight loss after 1 and 2 months

predicted weight loss at 4 and 8 years. ${ }^{77}$ It is essential to evaluate early weight reduction because the individual may lack other critical components for success (such as motivation or adherence to the program) and may require further assistance. ${ }^{66}$ For example, if early weight loss is not accomplished, the patient may benefit from using a different strategy for weight loss. ${ }^{66}$ 
The second variable that was found to predict weight loss success at 12 weeks was the frequency of weekly weight self-monitoring. The odds of losing $\geq 5 \%$ of baseline weight if the person always self-monitored their weekly weight was 33.53 times higher than the odds of losing weight if they never or sometimes self-monitored their weekly weight. This finding is consistent with a systematic review that found regular self-weighing was associated with successful weight loss, weight maintenance, and weight gain prevention in adults seeking behavioral weight loss treatment. ${ }^{43}$ Furthermore, 2 systematic reviews showed that significant weight loss in behavioral weight-loss interventions was associated with a commitment to self-monitoring weight-related behaviors (i.e., diet, weight, and physical activity). ${ }^{38,39}$ Also, some studies demonstrated that weekly weighing was associated with weight loss. ${ }^{13,14}$ Specifically, VanWormer et al ${ }^{53}$ found that participants who lost $\geq 5 \%$ of their pretreatment weight were significantly more likely to selfweight at least weekly than those who self-weighed less than weekly (46\% vs. $8 \%$, modeled OR_11.1[3.0, 41.2], $\mathrm{p}<0.001)$. In contrast, Lally et al. ${ }^{42}$ reported no differences between weekly and monthly weighing in their study that evaluated the efficacy of a simple weight loss intervention based on principles of habit formation.

No previous weight loss attempts also predicted weight loss $(\geq 5 \%)$ at 12 weeks in the current study. The odds of losing weight if a person did not use a program to lose weight in the past was 63.82 times higher than the odds of losing weight if the person used a program in the past. This finding is consistent with previous research that explained that individuals who have tried and failed to lose weight before might have low self-confidence and self-trust, resulting in poor acceptance and success following attempts. ${ }^{67}$ Additionally, those who attended the weightloss trial with no prior experience with professional weight loss assistance may have acquired new skills and knowledge and received support for the first time. 
Final Predictors Factors for Percentage of Weight Loss at 6 Weeks $(\geq 3.5 \%,<3.5 \%$ weight loss)

The data suggested that a change in HEI scores at 6 weeks predicted success of $\geq 3.5 \%$ weight loss at 6 weeks. The odds ratio indicated that for every 1 point increase in the change HEI scores at 6 weeks, the probability that a person lost $\geq 3.5 \%$ of baseline weight increased by approximately 1.08 times. Our findings are consistent with Christifano et al. (2016), who examined diet quality changes as measured by the HEI-2010 during a weight loss intervention among breast cancer survivors. ${ }^{68}$ They found that more improvement in diet quality scores from baseline to 6 months was associated with more weight reduction at 6 months. An online weight loss program in overweight and obese adults in Australia reported similar results. ${ }^{69}$ However, they measured the diet quality scores using the Australian Recommended Food Score rather than the HEI scores. Poor diet quality is a crucial risk factor for chronic diseases. Diets that score high in diet quality have been linked to a lower risk of chronic disease (i.e., cancer, cardiovascular disease incidence and mortality, type 2 diabetes, and neurodegenerative diseases) and overall mortality. ${ }^{70}$

The results of our study indicate that having a family member to eat better during the study was also a predictor of $\geq 3.5 \%$ weight loss at 6 weeks. The odds of losing weight if the person perceived that the family member had started to eat better along with them was 4.96 times higher than the odds if the participant responded neutral or disagreed on the survey response. Social support includes obtaining information, encouragement, emotional support, and enhancing the environment to support behavior change from family, friends, colleagues, and health professionals. ${ }^{45}$ Other studies also found associations between social support and weight loss outcomes. There was a positive relationship between social support from friends and family and weight loss in other weight loss studies. ${ }^{49,50}$ For example, friend support for healthy eating 
( $\beta=-0.15)$, coworker support for healthy eating $(\beta=-0.11)$, and family support for physical activity $(\beta=-0.032)$ was reported to be associated with weight reduction at 24 months $(P$-values $<0.05$ ) in one study. ${ }^{56}$ Another study found that participants who never experienced family support were least likely to lose weight $(45.7 \%$ lost $\geq 5 \%$ of initial weight) whereas participants who experienced both frequent friend and family support were more likely to lose weight (71.6\% lost $\geq 5 \%$ of initial weight). ${ }^{49,50}$

\section{Other Factors that Predict Weight Loss at 12 Weeks $(\geq 5 \%,<5 \%$ weight loss)}

Other factors in the bivariate analyses showed significant relationships with weight loss at 12 weeks ( $\geq 5 \%$ or $<5 \%$ ) but did not remain significant predictors after multivariate analysis. For example, the frequency of using the weekly meal planner was a significant factor in predicting $\geq$ $5 \%$ loss of baseline weight. The odds of losing weight if the person used the weekly meal planner for 4-6 weeks was 5.3 times higher than the odds of losing weight if the person used the weekly meal planner for 1-3 weeks, consistent with other studies. ${ }^{16,44}$ Also, the participants' self-efficacy was significant in predicting people's loss of $\geq 5 \%$ of baseline weight. Specifically, the odds ratio of losing weight if the person agreed on confidence in making the necessary changes to eat healthier and lose weight is 6.6 times higher than the odds ratio if the person had a neutral or disagree response. This finding supports the theory that improving self-efficacy is a fundamental technique for increasing the adoption of particular health behaviors. ${ }^{57}$ Many studies have shown the association between self-efficacy and change in weight over time. ${ }^{58,19,71}$ Contrary to this association, other research showed no link between increased self-efficacy and weight change. ${ }^{60}$

Additionally, having a partner who followed the program with the participant was a significant factor in predicting whether participants lost weight or had a stable weight. According to a systematic review of family involvement in weight control by McLean et al., ${ }^{51}$ there are mixed 
results for spouse's involvement. Sometimes there is an improved outcome, and sometimes there are better results for treating the members alone. Golan et al. ${ }^{17}$ examined the spouses' effect of a 2-year DIRECT study. They found a significantly more weight loss was achieved at 6 months if a spouse also enrolled in a weight loss program compared to when the spouse did not participate in the sessions ( $-5.2 \mathrm{~kg}$ versus $-3.5 \mathrm{~kg}, \mathrm{P}=0.020)$. Another study found that participants who had attended meetings with their spouses lost significantly more weight than participants who had experienced without their spouses at 1 and 2-year follow-ups. ${ }^{18}$ Also, participants in the intervention group that received behavioral support from an RDN were more likely to lose $\geq 5 \%$ of baseline weight at 12 weeks. ${ }^{21}$ Our finding is consistent with other studies. ${ }^{8,9,32}$ However, some studies found no significant differences between groups in percent of body weight loss. ${ }^{10,33}$

\section{Strengths and Limitations}

A strength of this study was that it collectively examined demographics, diet, early weight loss, and behavioral strategies (e.g., self-monitoring and social support) and constructs (i.e., selfefficacy) associated with weight loss among middle-aged and older men in Appalachia, thus adding to the scientific literature. There were some limitations to this study. The data were collected through a self-reported questionnaire which is subject to bias and random and systematic error. ${ }^{72}$ Another limitation is in respect to generalizability. The study sample included males who were high-income earners (nearly $56 \%$ had a household income $\geq$ of $\$ 75,000$ ), were highly educated (51.8\% had a college degree and $25 \%$ had some college or technical school education), and were mainly non-Hispanic whites. Therefore, the results may not generalize to other ethnic groups and men with lower socioeconomic status and lower educational levels.

\section{Practical Application}


The first few weeks of treatment are critical for participants in weight-loss interventions. Individuals who do not achieve early weight loss (i.e., $<3.5 \%$ at 6 weeks) may benefit from additional support or transition to alternative treatment options. Additionally, patients should be encouraged to self-monitor their weekly weight and dietary intake and be given easy techniques to help them adhere more consistently. For example, the convenience of using smartphone applications and other wearable technology may improve self-monitoring adherence.

\section{Future Research}

Additional research with larger sample size and target recruitment to low-income and low education level people are needed. Future research should consider identifying individuals with low initial weight loss (i.e., $<3.5 \%$ at 6 weeks) and examine whether it would be beneficial to modify treatment for these individuals. Future studies should also include other essential factors to help weight loss outcomes, such as physical activity, as recommended in clinical care guidelines for obesity treatment. Future interventions should use validated self-efficacy and social support scales such as Sallis et al. Eating Habits Confidence Survey and the Social Support for Diet Behavior Questionnaire ${ }^{73,74}$. Such studies may lead to a better understanding of how to tailor lifestyle interventions to help improve long-term weight loss success. 


\section{CHAPTER 6: CONCLUSION}

In conclusion, the current findings suggested that for overweight or obese male adults in Appalachia, weight loss in the first 6 weeks of a telenutrition weight loss intervention was predictive for losing $\geq 5 \%$ of baseline weight at 12 weeks. As a result, the initial few weeks of treatment may be an excellent opportunity to identify those who are most likely to fail at the end of treatment and offer them alternative therapy. Moreover, the results of this study support that increased self-monitoring of weekly weight may be related to better weight loss outcomes at the end of the intervention. Dietitians and other healthcare professionals should consider this behavioral strategy as a tool for promoting desired behavior change. In addition, higher diet quality change scores at 6 weeks were associated with a more significant percentage of early weight loss. 


\section{REFERENCES}

1. Hales CM, Carroll MD, Fryar CD, Ogden CL. Prevalence of obesity and severe obesity among adults: United States, 2017-2018. NCHS Data Brief. 2020;(360):1-8.

2. The State of obesity in West Virginia. State of Childhood Obesity. Accessed June 11, 2021. https://stateofchildhoodobesity.org/states/

3. Statistics about the population of West Virginia. West Virginia Department of Health and Human Resources Accessed April 13, 2021. https://dhhr.wv.gov/hpcd/data_reports/pages/fast-facts.aspx

4. Semper HM, Povey R, Clark-Carter D. A systematic review of the effectiveness of smartphone applications that encourage dietary self-regulatory strategies for weight loss in overweight and obese adults: Systematic review of smartphone applications for weight loss. Obes Rev. 2016;17(9):895-906. doi:10.1111/obr.12428

5. Kristal AR, Satia JA. Evaluation of Nutrition Interventions. In: Coulston AM, Boushey CJ, Delahanty LM, Ferruzzi MG. Nutrition in the Prevention and Treatment of Disease. Elsevier Science \& Technology; 2001: 123-138.

6. Klohe-Lehman DM, Freeland-Graves J, Anderson ER, et al. Nutrition knowledge is associated with greater weight loss in obese and overweight low-income mothers. J Am Diet Assoc. 2006;106(1):65-75. doi:10.1016/j.jada.2005.09.047

7. Jeffrey RW, Wing RR. Long-term effects of interventions for weight loss using food provision and monetary incentives. J Consult Clin Psychol. 1995;63(5):793-796. doi:10.1037/0022-006X.63.5.793

8. Alencar MK, Johnson K, Mullur R, Gray V, Gutierrez E, Korosteleva O. The efficacy of a telemedicine-based weight loss program with video conference health coaching support. J Telemed Telecare. 2019;25(3):151-157. doi:10.1177/1357633X17745471

9. Ahrendt AD, Kattelmann KK, Rector TS, Maddox DA. The Effectiveness of telemedicine for weight management in the MOVE! program. J Rural Health. Published online 2014:7.

10. Taetzsch A, Gilhooly CH, Bukhari A, et al. Development of a videoconference-adapted version of the community diabetes prevention program, and comparison of weight loss with in-person program delivery. Mil Med. 2019;184(11-12):647-652. doi:10.1093/milmed/usz069

11. Chad-Friedman E, Pearsall M, Miller KM, et al. Total lifestyle coaching: a pilot study evaluating the effectiveness of a mind-body and nutrition telephone coaching program for obese adults at a community health center. Glob Adv Health Med.

2018;7:2164956118784902. doi:10.1177/2164956118784902 
12. Weinstock RS, Trief PM, Cibula D, Morin PC, Delahanty LM. Weight loss success in metabolic syndrome by telephone interventions: results from the SHINE Study. J Gen Intern Med. 2013;28(12):1620-1628. doi:10.1007/s11606-013-2529-7

13. VanWormer JJ, Martinez AM, Martinson BC, et al. Self-weighing promotes weight loss for obese adults. Am J Prev Med. 2009;36(1):70-73. doi:10.1016/j.amepre.2008.09.022

14. VanWormer JJ, Linde JA, Harnack LJ, Stovitz SD, Jeffery RW. Self-weighing frequency is associated with weight gain prevention over 2 years among working adults. Int $\mathbf{J}$ Behav Med. 2012;19(3):351-358. doi:10.1007/s12529-011-9178-1

15. Hollis JF, Gullion CM, Stevens VJ, et al. Weight loss during the intensive intervention phase of the weight-loss maintenance trial. Am J Prev Med. 2008;35(2):118-126. doi:10.1016/j.amepre.2008.04.013

16. Ingels JS, Misra R, Stewart J, Lucke-Wold B, Shawley-Brzoska S. The effect of adherence to dietary tracking on weight loss: using HLM to model weight loss over time. J Diabetes Res. 2017;2017.

17. Golan R, Schwarzfuchs D, Stampfer MJ, Shai I. Halo effect of a weight-loss trial on spouses: the DIRECT-Spouse study. Public Health Nutr. 2010;13(4):544-549.

18. Murphy JK, Williamson DA, Buxton AE, Moody SC, Absher N, Warner M. The long-term effects of spouse involvement upon weight loss and maintenance. Behav Ther. 1982;13(5):681-693. doi:10.1016/S0005-7894(82)80024-5

19. Palmeira AL, Teixeira PJ, Branco TL, et al. Predicting short-term weight loss using four leading health behavior change theories. Int J Behav Nutr Phys Act. 2007;4:14. doi:10.1186/1479-5868-4-14

20. Roach J, Yadrick K, Johnson J, Boudreaux L, Forsythe W, Billon W. Using self-efficacy to predict weight loss among young adults. J Am Diet Assoc. 2003;103:1357-1359. doi:10.1016/S0002-8223(03)01072-1

21. Ventura Marra M, Lilly C, Nelson K, Woofter D, Malone J. A pilot randomized Controlled trial of a telenutrition weight loss intervention in middle-aged and older men with multiple risk factors for cardiovascular disease. Nutrients. 2019;11(2):229. doi:10.3390/nu11020229

22. Jensen MD, Ryan DH, Apovian CM, et al. 2013 AHA/ACC/TOS Guideline for the Management of Overweight and Obesity in Adults. J Am Coll Cardiol. 2014;63(25_Part_B):2985-3023.doi:10.1016/j.jacc.2013.11.004

23. Weight Management or Obesity. Nutrition care manual. Accessed June 8, 2021.https://www-nutritioncaremanual-

org.wvu.idm.oclc.org/topic.cfm?ncm_category_id=1\&lv1=272986\&lv2=16997\&lv3=2679 67\&ncm_toc_id=267967\&ncm_heading=Nutrition\%20Care. 
24. Raynor HA, Champagne CM. Position of the Academy of Nutrition and Dietetics: interventions for the treatment of overweight and obesity in adults. J Acad Nutr Diet. 2016;116(1):129-147. doi:10.1016/j.jand.2015.10.031

25. Wharton S, Lau DCW, Vallis M, et al. Obesity in adults: a clinical practice guideline. Can Med Assoc J. 2020;192(31):E875-E891. doi:10.1503/cmaj.191707

26. Nutrition terminology reference manual (eNCPT): Dietetics Language for Nutrition Care. Nutrition Intervention Terminology, 2020 Edition. Accessed December 6, 2021. https://www.ncpro.org/encpt-2020-edition-released.

27. Dietz WH, Baur LA, Hall K, et al. Management of obesity: improvement of health-care training and systems for prevention and care. The Lancet. 2015;385(9986):2521-2533. doi:10.1016/S0140-6736(14)61748-7

28. Bleich SN, Bandara S, Bennett W, Cooper LA, Gudzune KA. Enhancing the role of nutrition professionals in weight management: A cross-sectional survey. Obesity. 2015;23(2):454-460. doi:https://doi.org/10.1002/oby.20945

29. The Academy of Nutrition and Dietetics. Practicing Telehealth for Nutritionists and RDNs. Accessed April 13, 2021. https://www.eatrightpro.org/practice/practiceresources/telehealth/practicing-telehealth.

30. Academy of Nutrition and Dietetics. Telehealth. Academy of Nutrition and Dietetics Telehealth. https://www.eatrightpro.org/practice/practice-resources/telehealth. Academy of Nutrition and Dietetics. Telehealth. Accessed December 6, 2021. https://www.eatrightpro.org/practice/practice-resources/telehealth.

31. Rollo ME, Hutchesson MJ, Burrows TL, et al. Video consultations and virtual nutrition care for weight management. J Acad Nutr Diet. 2015;115(8):1213-1225. doi:10.1016/j.jand.2015.03.016

32. Johnson KE, Alencar MK, Coakley KE, et al. Telemedicine-based health coaching is effective for inducing weight loss and improving metabolic markers. Telemed E-Health. 2019;25(2):85-92. doi:10.1089/tmj.2018.0002

33. Vadheim LM, McPherson C, Kassner DR, et al. Adapted diabetes prevention program lifestyle intervention can be effectively delivered through telehealth. Diabetes Educ. 2010;36(4):651-656. doi:10.1177/0145721710372811

34. Wolever RQ, Eisenberg DM. What is health coaching anyway?: standards needed to enable rigorous research. Arch Intern Med. 2011;171(22):2017-2018. doi:10.1001/archinternmed.2011.508

35. Kelly JT, Reidlinger DP, Hoffmann TC, Campbell KL. Telehealth methods to deliver dietary interventions in adults with chronic disease: a systematic review and meta-analysis. Am J Clin Nutr. 2016;104(6):1693-1702. doi:10.3945/ajcn.116.136333 
36. Stuart KL, Wyld B, Bastiaans K, et al. A telephone-supported cardiovascular lifestyle programme (CLIP) for lipid reduction and weight loss in general practice patients: a randomised controlled pilot trial. Public Health Nutr. 2014;17(3):640-647. doi:10.1017/S1368980013000220

37. Wilde MH, Garvin S. A concept analysis of self-monitoring. J Adv Nurs. 2007;57(3):339350. doi:10.1111/j.1365-2648.2006.04089.x

38. Madigan CD, Daley AJ, Lewis AL, Aveyard P, Jolly K. Is self-weighing an effective tool for weight loss: a systematic literature review and meta-analysis. Int J Behav Nutr Phys Act. 2015;12:104. doi:10.1186/s12966-015-0267-4

39. Burke LE, Wang J, Sevick MA. Self-monitoring in weight loss: a systematic review of the literature. J Am Diet Assoc. 2011;111(1):92-102. doi:10.1016/j.jada.2010.10.008

40. Butryn ML, Phelan S, Hill JO, Wing RR. Consistent self-monitoring of weight: a key component of successful weight loss maintenance. Obes Silver Spring Md. 2007;15(12):3091-3096. doi:10.1038/oby.2007.368

41. Welsh EM, Sherwood NE, VanWormer JJ, Hotop AM, Jeffery RW. Is frequent selfweighing associated with poorer body satisfaction? Findings from a phone-based weight loss trial. J Nutr Educ Behav. 2009;41(6):425-428. doi:10.1016/j.jneb.2009.04.006

42. Lally P, Chipperfield A, Wardle J. Healthy habits: efficacy of simple advice on weight control based on a habit-formation model. Int J Obes. 2008;32(4):700-707.

43. Zheng Y, Klem ML, Sereika SM, Danford CA, Ewing LJ, Burke LE. Self-weighing in weight management: A systematic literature review. Obesity. 2015;23(2):256-265.

44. Tronieri JS, Fabricatore AN, Wadden TA, et al. Effects of dietary self-monitoring, physical activity, liraglutide $3.0 \mathrm{mg}$, and placebo on weight loss in the SCALE IBT trial. Obes Facts. 2020;13(6):572-583. doi:10.1159/000511130

45. Lee SM, Kim EM, Kim WK, et al. International dietetics \& nutrition terminology (INDT) Reference manual, Standardized language for the nutrition care process-(translated version). Engl Orig Writ Am Diet Assoc. Published online 2011:13-354.

46. Spahn JM, Reeves RS, Keim KS, et al. State of the evidence regarding behavior change theories and strategies in nutrition counseling to facilitate health and food behavior change. J Am Diet Assoc. 2010;110(6):879-891.

47. Pearson ES. Goal setting as a health behavior change strategy in overweight and obese adults: a systematic literature review examining intervention components. Patient Educ Couns. 2012;87(1):32-42.

48. Brown C, Goetz J, Hamera E. Weight loss intervention for people with serious mental illness: a randomized controlled trial of the RENEW program. Psychiatr Serv. 2011;62(7):800-802. 
49. Wang ML, Pbert L, Lemon SC. Influence of family, friend and coworker social support and social undermining on weight gain prevention among adults. Obes Silver Spring Md. 2014;22(9):1973-1980. doi:10.1002/oby.20814

50. Kiernan M, Moore SD, Schoffman DE, et al. Social support for healthy behaviors: scale psychometrics and prediction of weight loss among women in a behavioral program. Obes Silver Spring Md. 2012;20(4):756-764. doi:10.1038/oby.2011.293

51. Family involvement in weight control, weight maintenance and weight-loss interventions: a systematic review of randomised trials | International Journal of Obesity. Accessed May 7, 2021. https://www.nature.com/articles/0802383

52. Wing RR, Marcus MD, Epstein LH, Jawad A. A "family-based" approach to the treatment of obese Type II diabetic patients. J Consult Clin Psychol. 1991;59(1):156-162. doi:10.1037/0022-006X.59.1.156

53. Black DR, Lantz CE. Spouse involvement and a possible long-term follow-up trap in weight loss. Behav Res Ther. 1984;22(5):557-562.

54. Jeffery RW, Bjornson-Benson WM, Rosenthal BS, Lindquist RA, Kurth CL, Johnson SL. Correlates of weight loss and its maintenance over two years of follow-up among middleaged men. Prev Med. 1984;13(2):155-168. doi:10.1016/0091-7435(84)90048-3

55. Rosenstock IM, Strecher VJ, Becker MH. Social learning theory and the Health Belief Model. Health Educ Q. 1988;15(2):175-183. doi:10.1177/109019818801500203

56. Bandura A. Self-efficacy: toward a unifying theory of behavioral change. Psychol Rev. 1977;84(2):191-215. doi:10.1037//0033-295x.84.2.191

57. Wingo BC, Desmond RA, Brantley P, et al. Self-efficacy as a predictor of weight change and behavior change in the PREMIER trial. J Nutr Educ Behav. 2013;45(4):314-321. doi:10.1016/j.jneb.2012.12.004

58. Bernier M, Avard J. Self-efficacy, outcome, and attrition in a weight-reduction program. Cogn Ther Res. 10(3):319-338.

59. Fontaine KR, Cheskin LJ. Self-efficacy, attendance, and weight loss in obesity treatment. Addict Behav. 1997;22(4):567-570. doi:10.1016/s0306-4603(96)00068-8

60. Martin PD, Dutton GR, Brantley PJ. Self-efficacy as a predictor of weight change in African-American women. Obes Res. 2004;12(4):646-651. doi:10.1038/oby.2004.74

61. Harris PA, Taylor R, Thielke R, Payne J, Gonzalez N, Conde JG. Research electronic data capture (REDCap) — A metadata-driven methodology and workflow process for providing translational research informatics support. J Biomed Inform. 2009;42(2):377-381. doi:10.1016/j.jbi.2008.08.010 
62. WHO Expert Committee on Physical Status : the Use and Interpretation of Anthropometry (1993 : Geneva, Switzerland) \& World Health Organization. (1995). Physical status : the use of and interpretation of anthropometry, report of a WHO expert committee. World Health Organization. Accessed November 7, 2021. https://apps.who.int/iris/handle/10665/37003

63. Developing the Healthy Eating Index (HEI) |EGRP/DCCPS/NCI/NIH. Accessed November 7, 2021. https://epi.grants.cancer.gov/hei/developing.html

64. Unick JL, Hogan PE, Neiberg RH, et al. Evaluation of early weight loss thresholds for identifying nonresponders to an intensive lifestyle intervention. Obesity. 2014;22(7):16081616.

65. Unick JL, Neiberg RH, Hogan PE, et al. Weight change in the first 2 months of a lifestyle intervention predicts weight changes 8 years later. Obesity. 2015;23(7):1353-1356.

66. Gow ML, Baur LA, Ho M, et al. Can early weight loss, eating behaviors and socioeconomic factors predict successful weight loss at 12- and 24-months in adolescents with obesity and insulin resistance participating in a randomised controlled trial? Int $\mathbf{J}$ Behav Nutr Phys Act. 2016;13:43. doi:10.1186/s12966-016-0367-9

67. Wooley SC, Garner DM. Obesity treatment: the high cost of false hope. J Am Diet Assoc. 1991;91(10):1248-1251.

68. Christifano DN, Fazzino TL, Sullivan DA, Befort CA. Diet quality of breast cancer survivors after a six-month weight management intervention: Improvements and association with weight loss. Nutr Cancer. 2016;68(8):1301-1308.

doi:10.1080/01635581.2016.1224368

69. O’Brien KM, Hutchesson MJ, Jensen M, Morgan P, Callister R, Collins CE. Participants in an online weight loss program can improve diet quality during weight loss: a randomized controlled trial. Nutr J. 2014;13(1):1-8.

70. Schwingshackl L, Hoffmann G. Diet quality as assessed by the healthy eating index, the alternate healthy eating index, the dietary approaches to stop hypertension score, and health outcomes: A systematic review and meta-analysis of cohort studies. J Acad Nutr Diet. 2015;115(5):780-800.e5. doi:10.1016/j.jand.2014.12.009

71. Roach JB, Yadrick MK, Johnson JT, Boudreaux LJ, Forsythe WA, Billon W. Using selfefficacy to predict weight loss among young adults. J Am Diet Assoc. 2003;103(10):13571359. doi:10.1016/s0002-8223(03)01072-1

72. Ferranti EP, Narayan KMV, Reilly CM, et al. Dietary self-efficacy predicts AHEI diet quality in women with previous gestational diabetes. Diabetes Educ. 2014;40(5):688-699. doi:10.1177/0145721714539735 
73. Sallis JF, Pinski RB, Grossman RM, Patterson TL, Nader PR. The development of selfefficacy scales for healthrelated diet and exercise behaviors. Health Educ Res.

1988;3(3):283-292. doi:10.1093/her/3.3.283

74. Sallis JF, Grossman RM, Pinski RB, Patterson TL, Nader PR. The development of scales to measure social support for diet and exercise behaviors. Prev Med. 1987;16(6):825-836. doi:10.1016/0091-7435(87)90022-3 


\section{APPENDIX A}

\section{Data Analysis}

All statistical analyses were conducted using JMP software (JMP®, Version Pro 16.0.0, SAS Institute Inc., Cary, NC, 2021). Bivariate analyses were performed to determine the relationship between baseline characteristics, weight/body composition, and dietary factors, as well as constructs/strategy-related factors with continuous percent of weight loss at 6 and 12 weeks and continuous HEI (baseline and change at 6 and 12 weeks). Assumptions for parametric tests were tested using Shapiro-Wilk W test (normality of distribution) and Levene test (homogeneity of variance) on continuous response variables (percent of weight loss at 6 and 12 weeks, HEI at baseline, and change at 6 and 12 weeks). Simple linear regression analysis was performed on pairs of continuous regressors and continuous response variables (Ln-transformed of \% Weight loss at 12 weeks, percent of weight loss at 6 weeks, HEI at baseline, and change at 6 and 12 weeks). Nonparametric correlation analysis (Spearman's Rho) was used for ordinal independent variables with 3 or more ordinal levels vs. continuous response variables (percent of weight loss at 6 and 12 weeks, HEI, at baseline, and change at 6 and 12 weeks). Variable pairs with categorical independent variables vs. continuous response variables (Ln-transformed of \% weight loss at 12 weeks, percent of weight loss at 6 weeks, HEI at baseline and change at 6 and 12 weeks, individually) were analyzed by independent t-test. Unless otherwise noted, statistical significance was defined at $\alpha=0.05$. For 2 response variables (weight loss at 6 and 12 weeks continuous), multivariate models utilized the stepwise procedure with backward elimination using a lowest Bayesian information criterion (BIC) as a selection tool. Selection of variables used in multivariate analyses was based on the significant variables from the earlier bivariate analyses, and stepwise procedures were done in consecutive steps. In step 1, the 4 among the continuous variables that affected the weight loss at 6 weeks on a continuous scale were utilized. In step 2, a similar stepwise 
approach was used with the 12 categorical variables. In step 3, a narrower pool of candidate variables from both continuous and categorical models (step 1 and 2) was utilized in a final model in a stepwise analysis. Similarly, the weight loss at 12 weeks was analyzed, starting with 6 independent continuous and 11 categorical variables from the bivariate fits. Parameter estimates (intercept and slopes with corresponding p-values) are reported for the specific change of regressor variable.

\section{Factors Associated with Percentage of Weight Loss at 6 and 12 Weeks (continuous}

\section{response)}

Associations between the percentage of weight loss at 6 and 12 weeks (continuous variables) and baseline characteristics are reported in Table A1. A greater percent of weight loss at 6 weeks was significantly associated with: non-Hispanic/Whites, higher baseline FFMI, no diabetes status, lower numbers of comorbidities, 2 years and more of maintained current body weight, and lower numbers of meals eaten in a restaurant per week. A greater percent of weight loss at 12 weeks was significantly associated with: no hypertension and diabetes status, lower numbers of comorbidities, 2 years and more of maintained current body weight, and lower numbers of meals eaten in a restaurant per week.

Effect of intervention components on the percentage of weight loss at 6 and 12 weeks (continuous variables) are reported in Table A 2. Percent of weight loss at 6 and 12 weeks was significantly affected by: HEI changes scores at 6 weeks, agreeing on the confidence that they can make the necessary changes to eat healthier and lose weight, agreeing on the confidence that they were adhering to recommendations in the Playbook, participants perceived spousal support, agreeing on the family started to eat better, agreeing on the conversations with friends, co-workers, or relatives about weight loss strategies they have learned in the program, and higher percent of 
different SMART goals met. Additionally, the percent of weight loss at 6 weeks was significantly associated with change in energy intake at 6 weeks, more use of weekly meal planner and fruit and vegetables tracker and agreeing on partner lost weight. Moreover, the percent of weight loss at 12 weeks was significantly associated with the percent of weight loss at 6 weeks, partner also followed program, received support from an RDN, a higher number of health coach call, a higher average of total minutes for health coach call, and higher total minutes for time with an RDN for both MNT and health coach call.

\begin{tabular}{|c|c|c|}
\hline Baseline Characteristics & $\begin{array}{l}\text { \% Weight loss } \\
\text { at } 6 \text { weeks }\end{array}$ & $\begin{array}{l}\text { \% Weight loss at } \\
12 \text { weeks }\end{array}$ \\
\hline & \multicolumn{2}{|c|}{$\beta$ (p-value), Rho ( $p$-value), ( $p$-value) } \\
\hline $\operatorname{Age}^{\beta}$ & NS & NS \\
\hline Age groups ${ }^{t}$ & NS & NS \\
\hline Ethnicity/Race ${ }^{\mathrm{t}}$ & 0.0476 & \multirow{3}{*}{ NS } \\
\hline Non-Hispanic/White only ${ }^{n, m}$ & (51) $3.5 \pm 2.7$ & \\
\hline Others $^{n, m}$ & (5) $0.92 \pm 2.7$ & \\
\hline Education ${ }^{\rho}$ & NS & NS \\
\hline Work status ${ }^{t}$ & NS & NS \\
\hline Income $^{\rho}$ & NS & NS \\
\hline Smoking status & NS & NS \\
\hline $\mathrm{BMI}^{\beta}$ & NS & NS \\
\hline BMI classification $^{\rho}$ & NS & NS \\
\hline Baseline FFMI $^{\beta}$ & $0.4215(0.0050)$ & NS \\
\hline Baseline weight ${ }^{\beta}$ & NS & NS \\
\hline \multicolumn{3}{|l|}{ Comorbidities } \\
\hline Hypertension $^{\mathrm{t}}$ & \multirow{3}{*}{ NS } & 0.0432 \\
\hline$Y_{e s}^{n, m}$ & & (46) $4.9 \pm 3.6$ \\
\hline$N o^{n, m}$ & & (10) $6.8 \pm 5.5$ \\
\hline Hyperlipidemia t & NS & NS \\
\hline Diabetes status $\rho$ & $0.3072(0.0213)$ & $0.3640(0.0058)$ \\
\hline Number of comorbidities ${ }^{\rho}$ & $-0.2831(0.034)$ & $-0.2765(0.039)$ \\
\hline Self-rated health ${ }^{\rho}$ & NS & $\mathrm{NS}$ \\
\hline Physical activity ${ }^{\mathrm{t}}$ & NS & NS \\
\hline Weight History, maintained current body weight ${ }^{\mathrm{t} 1}$ & 0.0374 & 0.0004 \\
\hline$\leq 1$ year & (36) $2.7 \pm 2.8$ & (31) $1.4 \pm 0.7$ \\
\hline$\geq 2$ years & (20) $4.3 \pm 2.5$ & (19) $2.0 \pm 0.4$ \\
\hline Previously attempted weight loss & NS & NS \\
\hline \multicolumn{3}{|l|}{ Diet } \\
\hline Energy, $\mathrm{kcal}^{\beta}$ & NS & NS \\
\hline Diet quality, HEI scores $(0-100)^{\beta}$ & NS & NS \\
\hline Number of meals eaten in a restaurant/week ${ }^{\rho}$ & $-0.3341(0.011)$ & $-0.2925(0.028)$ \\
\hline
\end{tabular}


Abbreviations: Body Mass Index (BMI); Fat-Free Mass Index (FFMI); Healthy Eating Index Scores (HEI); Not Significant (NS). ${ }^{\beta}$ Simple linear regression analysis was done on pairs of continuous variables, or after transformation (Ln-transformed \%Weight loss at 12 weeks), value reported estimate of slope $\beta$ (p-value). ${ }^{\rho}$ Nonparametric correlation analysis (Spearman's Rho) was used for ordinal variables (BMI classification, education, income, number of comorbidities, and self-rated health, maintained current body weight, number of meals eaten in a restaurant/week, and diabetes status) with three or more ordinal levels vs. Weight loss at 6 or 12 weeks. ${ }^{t}$ Variable pairs with categorical independent variables (age group, ethnicity/race, work status, smoking status, comorbidities (hypertension, hyperlipidemia), physical Activity, and used another program to lose weight in the past) and Weight loss at 6 and Ln-transformed-Weight loss at 12 weeks were analyzed by t-test $\left[{ }^{\mathrm{n}, \mathrm{m}}(\mathrm{n})\right.$ Means $\left.\pm \mathrm{SD}\right] .{ }^{1} \leq 1$ year $(<6$ months +6 months to 1 year +1 year $), \geq 2$ years ( $2-4$ years $+>4$ years).

\begin{tabular}{|c|c|c|}
\hline & $\begin{array}{c}\% \text { Weight loss } \\
\text { at } 6 \text { weeks }\end{array}$ & $\begin{array}{c}\% \text { Weight loss at } 12 \\
\text { weeks }\end{array}$ \\
\hline & \multicolumn{2}{|c|}{$\beta$ (p-value), Rho (p-value), (p-value) } \\
\hline \multicolumn{3}{|l|}{ Diet } \\
\hline Weight loss, $\%$ change at 6 weeks $\beta$ & - & $0.2112(<0.0001)$ \\
\hline FFMI at 6 weeks $\beta$ & - & $\mathrm{NS}$ \\
\hline Change energy intake $0-6$ weeks $\beta$ & $-0.0019(0.0076)$ & NS \\
\hline Change energy intake $0-12$ weeks ${ }^{\beta}$ & - & NS \\
\hline HEI change at 6 weeks $\beta$ & $0.0984(<0.0001)$ & $0.0207(0.0002)$ \\
\hline \multicolumn{3}{|l|}{ Strategies or Constructs } \\
\hline Self-monitoring weekly weight ${ }^{\rho}$ & NS & NS \\
\hline \multicolumn{3}{|l|}{ Self-monitoring diet } \\
\hline Using of meal planner ${ }^{\mathrm{t} 1}$ & 0.0227 & \multirow{3}{*}{ NS } \\
\hline 1-3 weeks & (40) $2.7 \pm 2.7$ & \\
\hline 4-6 weeks & (16) $4.6 \pm 2.6$ & \\
\hline Using of fruit and vegetable tracker ${ }^{\mathrm{t}}$ & 0.0375 & \multirow{3}{*}{ NS } \\
\hline 1-3 weeks & (37) $2.6 \pm 2.7$ & \\
\hline 4-6 weeks & (18) $4.3 \pm 2.5$ & \\
\hline \multicolumn{3}{|l|}{ Self-efficacy (confident that I ...) ${ }^{\mathrm{t}}$} \\
\hline know what changes to make & NS & NS \\
\hline can make the necessary changes & 0.0004 & 0.0010 \\
\hline Agree $^{n, m}$ & (37) $4.2 \pm 2.6$ & (36) $1.8 \pm 0.5$ \\
\hline Neutral or Disagree $^{n, m}$ & (19) $1.5 \pm 2.4$ & (19) $1.1 \pm 0.8$ \\
\hline am adhering to Playbook & 0.0056 & 0.0088 \\
\hline Agree $^{n, m}$ & (24) $4.5 \pm 2.6$ & (24) $1.9 \pm 0.5$ \\
\hline Disagree or Neutral ${ }^{n, m}$ & (31) $2.4 \pm 2.6$ & (25) $1.4 \pm 0.8$ \\
\hline \multicolumn{3}{|l|}{ Social support } \\
\hline Partner helps my efforts ${ }^{t}$ & 0.0094 & 0.0160 \\
\hline Helps my efforts $\mathrm{n}, \mathrm{m}$ & (42) $3.8 \pm 2.7$ & (38) $1.7 \pm 0.5$ \\
\hline Neither helps nor inhibits my efforts/ inhibit my efforts ${ }^{\mathrm{n}, \mathrm{m}}$ & (14) $1.6 \pm 2.6$ & (14) $1.2 \pm 0.8$ \\
\hline Partner also follows program ${ }^{\mathrm{t}}$ & \multirow{3}{*}{ NS } & 0.0475 \\
\hline$N o^{n, m}$ & & (28) $1.4 \pm 0.8$ \\
\hline$Y e s^{n, m}$ & & (22) $1.8 \pm 0.5$ \\
\hline Partner lost weight $^{\mathrm{t}}$ & 0.0111 & \multirow{3}{*}{ NS } \\
\hline Disagree or Neutral ${ }^{n, m}$ & (39) $2.7 \pm 2.7$ & \\
\hline Agree ${ }^{n, m}$ & (17) $4.7 \pm 2.6$ & \\
\hline Family started to eat better ${ }^{\rho}$ & NS & NS \\
\hline
\end{tabular}




\begin{tabular}{|c|c|c|}
\hline Conversations with my doctors ${ }^{\mathrm{t}}$ & NS & NS \\
\hline Conversations with friends and family 2,3 & $<0.0001$ & 0.0005 \\
\hline Disagree or Neutral $n, m$ & (15) $1.1 \pm 1.6$ & (11) $1.0 \pm 0.8$ \\
\hline Agree $n, m$ & (40) $4.1 \pm 2.7$ & (38) $1.8 \pm 0.5$ \\
\hline Intervention Group $^{t}$ & \multirow{3}{*}{ NS } & 0.0301 \\
\hline Enhanced Usual Care control group & & (25) $1.4 \pm 0.8$ \\
\hline Intervention group & & (25) $1.8 \pm 0.5$ \\
\hline \multicolumn{3}{|l|}{ RDN Behavior Support ${ }^{4}$} \\
\hline Health coach call frequency ${ }^{\beta}$ & NS & $0.0512(0.0216)$ \\
\hline Average health coach call ${ }^{\beta}$ & NS & $0.0247(0.0309)$ \\
\hline Time with an RDN (MNT + Health coach call) ${ }^{\beta}$ & NS & $0.0016(0.0293)$ \\
\hline$\%$ Of different SMART goals met ${ }^{\beta}$ & $0.0189(0.0214)$ & $0.0045(0.0214)$ \\
\hline
\end{tabular}

Abbreviations: Fat-Free Mass Index (FFMI); Healthy Eating Index Scores (HEI); Registered Dietitian Nutritionist (RDN); Medical Nutrition Therapy (MNT); SMART (Specific, Measurable, Attainable, Realistic, Time-bound); Not Significant (NS). ${ }^{\beta}$ Simple linear regression analysis was done on pairs of continuous variables, or after transformation (Ln-transformed \%Weight loss at 12 weeks), value reported estimate of slope $\beta$ (p-value). ${ }^{\rho}$ Nonparametric correlation analysis (Spearman's Rho) was used for ordinal variables (dietary self-monitoring, weekly weight self-monitoring, and partner has lost weight) with three or more ordinal levels vs. Weight loss at 6 or 12 weeks. ${ }^{t}$ Variable pairs with categorical independent variables (self-efficacy, partner helps my weight loss efforts, partner also follows program, family started to eat better, conversations with friends, co-workers, or relatives, and conversations with my doctors) and Weight loss at 6 and Ln-transformed-Weight loss at 12 weeks were analyzed by t-test $\left[{ }^{\mathrm{n}, \mathrm{m}}\right.$ (n) Means $\left.\pm \mathrm{SD}\right] .{ }^{1}{ }^{1}$-3 weeks (Rarely, Never, Sometimes), 4-6 weeks (Always, Often). ${ }^{2}$ Agree (Agree or Strongly Agree), Disagree or Neutral (Strongly Disagree or Disagree + Neutral). ${ }^{3}$ (About weight loss strategies I have learned in this program). ${ }^{4}$ Behavioral Support from Dietitian (at 6 weeks) used with \% Weight loss at 6 weeks and Behavioral Support from Dietitian (at 12 weeks) used with \% Weight loss at 12 weeks.

\section{Predictive models for Percentage of Weight Loss at 6 and 12 Weeks (continuous variables)}

For the percentage of weight loss at 6 weeks, variables significant in bivariate analysis were entered into the first round of selection in multivariate backward elimination. Significant variables from the first round were baseline FFMI, HEI change score at 6 weeks (continuous), ethnicity/ race, how often used weekly meal planner, partner has lost weight, and conversations with friends, co-workers, or relatives (categorical). These variables were entered into the second round of selection in stepwise backward regression. The final predictive model for continuous percent of weight loss at 6 weeks is shown in Table A3. The model indicated that participants who had more percent of weight loss at 6 weeks had: agreeing on partner has lost weight; agreeing on conversations with friends, co-workers, or relatives about weight loss strategies they have learned in the program; higher baseline FFMI; and higher HEI change score at 6 weeks. 


\begin{tabular}{|c|c|c|c|c|}
\hline \multicolumn{5}{|c|}{$\begin{array}{l}\text { Model 1. Effect of independent continuous variables onto the percentage weight loss at } 6 \text { weeks } \\
\text { (Continuous) }\end{array}$} \\
\hline & Estimate & Std Error & $\mathrm{t}$-value & p-value \\
\hline Intercept & -4.10 & 2.72 & -1.51 & 0.1371 \\
\hline Baseline FFMI & 0.27 & 0.12 & 2.23 & 0.0301 \\
\hline HEI change score at 6 weeks & 0.08 & 0.01 & 4.98 & $<0.0001$ \\
\hline \multicolumn{5}{|c|}{$\begin{array}{l}\text { Model 2. Effect of independent categorical variables onto the percentage weight loss at } 6 \text { weeks } \\
\text { (Continuous) }\end{array}$} \\
\hline & Estimate & Std Error & t-value & p-value \\
\hline Intercept & 2.38 & 0.55 & 4.28 & $<0.0001$ \\
\hline Ethnicity/ race (Others) & -1.13 & 0.51 & -2.20 & 0.0323 \\
\hline Often used weekly meal planner (1-3 weeks) & -0.77 & 0.33 & -2.33 & 0.0239 \\
\hline Partner has lost weight (Disagree or Neutral) $^{2}$ & -0.74 & 0.33 & -2.22 & 0.0310 \\
\hline $\begin{array}{l}\text { Conversations with friends, co-workers, or relatives } \\
\text { (Disagree or Neutral) }\end{array}$ & -1.35 & 0.33 & -4.06 & 0.0002 \\
\hline \multicolumn{5}{|c|}{$\begin{array}{l}\text { Final model. Effect of independent continuous and categorical variables onto the percentage weight } \\
\text { loss at } 6 \text { weeks (Continuous) }\end{array}$} \\
\hline & Estimate & Std Error & t-value & p-value \\
\hline Intercept & -4.38 & 2.44 & -1.79 & 0.0790 \\
\hline Partner has lost weight (Disagree or Neutral) ${ }^{2}$ & -0.88 & 0.29 & -3.00 & 0.0042 \\
\hline $\begin{array}{l}\text { Conversations with friends, co-workers, or relatives } \\
\text { (Disagree or Neutral) }\end{array}$ & -0.77 & 0.34 & -2.27 & 0.0278 \\
\hline Baseline FFMI & 0.30 & 0.11 & 2.73 & 0.0087 \\
\hline HEI change score at 6 weeks & 0.06 & 0.01 & 3.35 & 0.0015 \\
\hline
\end{tabular}

Abbreviations: Fat Free Mass Index (FFMI); Healthy Eating Index Scores (HEI). ${ }^{1}$ Multivariate models utilized the stepwise procedure with backward elimination using a lowest Bayesian information criterion (BIC) as a selection tool. Selection of variables used in multivariate analyses was based on the significant variables from the earlier bivariate analyses and stepwise procedures were done in consecutive steps. In step one, the four among the continuous variables that affected the weight loss at 6 weeks on a continuous scale, were utilized. In step two, similar stepwise approach was used with the 12 categorical variables. Step three, a narrower pool of candidate variables from both continuous and categorical models (step one and two) was utilized in a final model in a stepwise analysis [partner has lost weight and conversation with friends and family are categorical (nominal) variables and reference groups are listed in parentheses for parameter estimates]. ${ }^{2}$ Disagree or Neutral (Strongly Disagree or Disagree + Neutral). 
For the percentage of weight loss at 12 weeks, variables significant in bivariate analysis were entered into the first round of selection in multivariate backward elimination. Significant variables from the first round were percent weight loss change at 6 weeks; average total minutes of health coach call (continuous); maintained current body weight; confidence that they can make the necessary changes to eat healthier and lose weight; and conversations with friends, co-workers, or relatives (categorical). These variables were entered into the second round of selection in stepwise backward regression. The final predictive model for continuous percent of weight loss at 12 weeks is shown in Table A4. The model indicates that participants who had more percent of weight loss at 12 weeks had: 2 years or more of maintained current body weight, and higher percent weight loss change at 6 weeks.

The final alternative predictive model for continuous percent of weight loss at 12 weeks without using \% weight loss changes at 6 weeks in the model is shown in Table A5. The model indicates that participants who had more percent of weight loss at 12 weeks had: two years and more of maintained current body weight, agreeing on the confidence that they can make the necessary changes to eat healthier and lose weight, and agreed on the conversations with friends, co-workers, or relatives about weight loss strategies they have learned in the program. 


\begin{tabular}{|c|c|c|c|c|}
\hline \multicolumn{5}{|c|}{ Model 1. Effect of independent continuous variables onto the percentage weight loss at 12 weeks (Continuous) } \\
\hline & Estimate & Std Error & t-value & p-value \\
\hline Intercept & 0.74 & 0.09 & 7.57 & $<0.0001$ \\
\hline Percent weight loss change at 6 weeks & 0.20 & 0.02 & 9.96 & $<0.0001$ \\
\hline Average health coach call & 0.01 & 0.006 & 2.29 & 0.0268 \\
\hline \multicolumn{5}{|c|}{ Model 2. Effect of independent categorical variables onto the percentage weight loss at 12 weeks (Continuous) } \\
\hline & Estimate & Std Error & $\mathrm{t}$-value & $\mathrm{p}$-value \\
\hline Intercept & 1.36 & 0.10 & 12.93 & $<0.0001$ \\
\hline Weight history (maintained weight) $\left(\leq 1\right.$ year) ${ }^{2}$ & -0.16 & 0.08 & -2.00 & 0.0515 \\
\hline $\begin{array}{l}\text { Confident I can make the necessary changes to eat } \\
\text { healthier and lose weight (Agree) }\end{array}$ & 0.24 & 0.09 & 2.74 & 0.0088 \\
\hline $\begin{array}{l}\text { Conversations with friends, co-workers, or relatives } \\
\text { (Disagree or Neutral) }\end{array}$ & -0.31 & 0.09 & -3.31 & 0.0019 \\
\hline \multicolumn{5}{|c|}{$\begin{array}{l}\text { Final model. Effect of independent continuous and categorical variables onto the percentage weight loss at } 12 \\
\text { weeks (Continuous) }\end{array}$} \\
\hline & Estimate & Std Error & $\mathrm{t}$-value & p-value \\
\hline Intercept & 0.92 & 0.09 & 9.91 & $<0.0001$ \\
\hline Weight history (maintained weight) ( $\leq 1$ year) ${ }^{2}$ & -0.16 & 0.05 & -3.02 & 0.0041 \\
\hline Percent weight loss change at 6 weeks & 0.19 & 0.02 & 9.72 & $<0.0001$ \\
\hline
\end{tabular}

${ }^{1}$ Multivariate models utilized the stepwise procedure with backward elimination using a lowest Bayesian information criterion (BIC) as a selection tool. Selection of variables used in multivariate analyses was based on the significant variables from the earlier bivariate analyses and stepwise procedures were done in consecutive steps. In step one, the six among the continuous variables that affected the weight loss at 12 weeks on a continuous scale, were utilized. In step two, similar stepwise approach was used with the 11 categorical variables. Step three, a narrower pool of candidate variables from both continuous and categorical models (step one and two) was utilized in a final model in a stepwise analysis [weight history, confident can make the necessary changes, and conversation with friends and family are categorical (nominal) variables and reference groups are listed in parentheses for parameter estimates]. ${ }^{2} \leq 1$ year $(<6$ months +6 months to 1 year +1 year $).{ }^{3}$ Disagree or Neutral (Strongly Disagree or Disagree + Neutral). 


\begin{tabular}{|c|c|c|c|c|}
\hline \multicolumn{5}{|c|}{$\begin{array}{l}\text { Table A5. Alternative multivariate analysis for all factors potentially affecting participants the percentage weight } \\
\text { loss at } 12 \text { weeks (Continuous) without } \% \text { weight loss changes at } 6 \text { weeks } 1\end{array}$} \\
\hline \multicolumn{5}{|c|}{ Model 1. Effect of independent continuous variables onto the percentage weight loss at 12 weeks (Continuous) } \\
\hline & Estimate & Std Error & t-value & p-value \\
\hline Intercept & 1.27 & 0.11 & 10.88 & $<0.0001$ \\
\hline HEI change score at 6 weeks & 0.02 & 0.005 & 4.06 & 0.0002 \\
\hline \multicolumn{5}{|c|}{ Model 2. Effect of independent categorical variables onto the percentage weight loss at 12 weeks (Continuous) } \\
\hline & Estimate & Std Error & t-value & p-value \\
\hline Intercept & 1.36 & 0.10 & 12.93 & $<0.0001$ \\
\hline Weight history (maintained weight $)(\leq 1 \text { year })^{2}$ & -0.16 & 0.08 & -2.00 & 0.0515 \\
\hline $\begin{array}{l}\text { Confident I can make the necessary changes to eat } \\
\text { healthier and lose weight (Agree) }\end{array}$ & 0.24 & 0.09 & 2.74 & 0.0088 \\
\hline $\begin{array}{l}\text { Conversations with friends, co-workers, or relatives } \\
\text { (Disagree or Neutral) }{ }^{3}\end{array}$ & -0.31 & 0.09 & -3.31 & 0.0019 \\
\hline \multicolumn{5}{|c|}{$\begin{array}{l}\text { Final model. Effect of independent continuous and categorical variables onto the percentage weight loss at } 12 \\
\text { weeks (Continuous) }\end{array}$} \\
\hline & Estimate & Std Error & t-value & p-value \\
\hline Intercept & 1.36 & 0.10 & 12.93 & $<0.0001$ \\
\hline Weight history (maintained weight) $\left(\leq 1\right.$ year) ${ }^{2}$ & -0.16 & 0.08 & -2.00 & 0.0515 \\
\hline $\begin{array}{l}\text { Confident I can make the necessary changes to eat } \\
\text { healthier and lose weight (Agree) }\end{array}$ & 0.24 & 0.09 & 2.74 & 0.0088 \\
\hline $\begin{array}{l}\text { Conversations with friends, co-workers, or relatives } \\
\text { (Disagree or Neutral) }{ }^{3}\end{array}$ & -0.31 & 0.09 & -3.31 & 0.0019 \\
\hline
\end{tabular}

Abbreviations: Healthy Eating Index Scores (HEI). ${ }^{1}$ Multivariate models utilized the stepwise procedure with backward elimination using a lowest Bayesian information criterion (BIC) as a selection tool. Selection of variables used in multivariate analyses was based on the significant variables from the earlier bivariate analyses, and stepwise procedures were done in consecutive steps. In step one, the five among the continuous variables that affected the weight loss at 12 weeks on a continuous scale, were utilized. In step two, a similar stepwise approach was used with the 11 categorical variables. Step three, a narrower pool of candidate variables from both continuous and categorical models (step one and two) was utilized in a final model in a stepwise analysis [weight history, confident can make the necessary changes, and conversation with friends and family are categorical (nominal) variables and reference groups are listed in parentheses for parameter estimates]. ${ }^{2} \leq 1$ year $(<6$ months +6 months to 1 year +1 year $) .{ }^{3}$ Disagree or Neutral (Strongly Disagree or Disagree + Neutral).

\section{Factors Associated with Dietary Outcomes}

Table A6 shows the bivariate analysis of the dietary outcomes by baseline characteristics of participants who completed the telenutrition weight loss intervention program. Age in years was positively correlated with HEI at baseline. Also, there were significant differences between age groups and HEI at baseline and change 6 and 12 weeks. The diabetes status was negatively correlated with HEI at baseline and positively correlated with HEI change score at 6 and 12 weeks. 


\begin{tabular}{|c|c|c|c|}
\hline \multicolumn{4}{|c|}{$\begin{array}{l}\text { Table A 6. Bivariate analysis of dietary outcomes (HEI) by baseline characteristics potentially } \\
\text { affecting if a participant lost weight }\end{array}$} \\
\hline & HEI WO & $\Delta$ HEI W6 & $\Delta$ HEI W12 \\
\hline Age $\beta$, years & $0.4974(0.035)$ & NS & NS \\
\hline Age groups ${ }^{t}$ & 0.0109 & 0.0422 & 0.0385 \\
\hline$<65$ years of age $e^{n, m}$ & (37) $48.5 \pm 11.88$ & (37) $17.1 \pm 16.7$ & (37) $18.6 \pm 16.7$ \\
\hline$>65$ years of age $e^{n, m}$ & (18) $57.8 \pm 12.97$ & (18) $7.2 \pm 16.2$ & (18) $8.8 \pm 14.8$ \\
\hline Ethnicity/Race $^{\mathrm{t}}$ & NS & NS & $\mathrm{NS}$ \\
\hline Education $^{\rho}$ & NS & NS & NS \\
\hline Work status $^{t}$ & NS & NS & NS \\
\hline Income $^{\rho}$ & NS & NS & NS \\
\hline Smoking status ${ }^{t}$ & NS & NS & NS \\
\hline $\mathrm{BMI}^{\beta}, \mathrm{kg} / \mathrm{m}^{2}$ & NS & NS & NS \\
\hline BMI Classification $^{\rho}$ & NS & NS & NS \\
\hline Baseline FFMI ${ }^{\beta}$ & NS & NS & NS \\
\hline Baseline Weight ${ }^{\beta}, \mathrm{kg}$ & NS & NS & NS \\
\hline \multicolumn{4}{|l|}{ Comorbidities } \\
\hline Hypertension $^{\mathrm{t}}$ & NS & NS & NS \\
\hline Hyperlipidemia $^{\mathrm{t}}$ & NS & NS & NS \\
\hline Diabetes Status $^{\rho}$ & $-0.2815(0.0356)$ & $0.3675(0.0053)$ & $0.2904(0.0299)$ \\
\hline Number of comorbidities ${ }^{\rho}$ & NS & NS & NS \\
\hline Self-rated health ${ }^{\rho}$ & NS & NS & NS \\
\hline Physical activity ${ }^{\mathrm{t}}$ & NS & NS & NS \\
\hline Maintained current body weight ${ }^{\rho}$ & NS & NS & NS \\
\hline
\end{tabular}

Abbreviations: Fat-Free Mass Index (FFMI); Body Mass Index (BMI); Healthy Eating Index Scores (HEI); Not Significant (NS). ${ }^{\beta}$ Simple linear regression analysis was done on pairs of continuous variables, value reported estimate of slope $\beta$ (p-value). ${ }^{\rho}$ Nonparametric correlation analysis (Spearman's Rho) was used for ordinal variables (diabetes status, maintained current body weight, BMI Classification, education, income, number of comorbidities, general health, and diabetes status) with three or more ordinal levels vs. HEI (W0, change W6, change W12). ${ }^{t}$ Variable pairs with categorical independent variables (age group, ethnicity/race, work status, smoking status, comorbidities (hypertension, hyperlipidemia), physical Activity) vs. HEI (W0, change W6, change W12) were analyzed by t-test [n, ${ }^{\mathrm{n}}(\mathrm{n})$ Means \pm SD] .

Table A7 shows the bivariate analysis of dietary outcomes by intervention components potentially affecting if a participant lost weight. The higher percentage of weight loss at 6 weeks was correlated with a higher HEI change score at 6 and 12 weeks. At the same time, the percentage of weight loss at 12 weeks was negatively correlated with HEI total score at baseline and positively correlated with HEI change score at 6 and 12 weeks. In addition, there were significant differences between the frequency of using self-monitoring weekly weight and the HEI change score at 6 weeks $(\mathrm{p}=0.0073)$. Also, there were significant differences between agreeing or neutral/ disagreeing on the confidence that they can make the necessary changes to eat healthier and lose 
weight and the HEI change score at 6 and 12 weeks. Similarly, there were significant differences between agreeing or neutral/ disagreeing on the confidence that they were adhering to recommendations in the Playbook and the HEI change score at 6 and 12 weeks. Also, there were significant differences between the conversation with their doctors and with friends, co-workers, or relatives and the HEI change score at 6 and 12 weeks. The behavioral support from an RDN positively correlated with the HEI change score at 6 weeks in terms of the numbers of health coach calls, average total minutes for health coach calls, total minutes with an RDN (MNT + Health coach call) and the percentage of different goals met. Only the HEI change score at 12 weeks was positively correlated with the percentage of different goals met at 6 weeks. 


\begin{tabular}{|c|c|c|c|}
\hline & HEI WO & $\triangle$ HEI W6 & $\triangle$ HEI W12 \\
\hline \multicolumn{4}{|l|}{ Weight loss, \% } \\
\hline Change at 6 weeks ${ }^{\beta}$ & NS & $3.6246(<0.0001)$ & $2.6644(0.0005)$ \\
\hline Change at 12 weeks $^{\beta}$ & $\begin{array}{l}-0.9380 \\
(0.029)\end{array}$ & $2.5131(<0.0001)$ & $2.415(<0.0001)$ \\
\hline FFMI at 6 weeks ${ }^{\beta}$ & NS & NS & NS \\
\hline \multicolumn{4}{|l|}{ Strategies or Constructs } \\
\hline Self-monitoring weekly weight ${ }^{\mathrm{t}}$ & NS & 0.0073 & NS \\
\hline \multicolumn{4}{|l|}{ Self-monitoring diet (week 6) } \\
\hline Meal planner -use- ${ }^{t}$ & NS & NS & NS \\
\hline Fruit and vegetable tracker-use- ${ }^{t}$ & NS & NS & NS \\
\hline \multicolumn{4}{|l|}{ Self-efficacy (confident that I ...), ${ }^{\mathrm{t}}$} \\
\hline know what changes to make & NS & NS & NS \\
\hline can make the necessary changes & \multirow{3}{*}{ NS } & 0.0071 & 0.0126 \\
\hline Agree ${ }^{n, m}$ & & (37) $18.2 \pm 15.6$ & (37) $19.6 \pm 15.7$ \\
\hline Neutral or Disagree ${ }^{n, m}$ & & (19) $5.6 \pm 16.8$ & (19) $8.1 \pm 16.0$ \\
\hline am adhering to Playbook. & \multirow{3}{*}{ NS } & 0.0043 & 0.0189 \\
\hline Agree $^{n, m}$ & & (24) $21.6 \pm 15.3$ & (24) $21.7 \pm 17.4$ \\
\hline Neutral or Disagree ${ }^{n, m}$ & & (31) $9.1 \pm 15.4$ & (31) $11.2 \pm 14.9$ \\
\hline \multicolumn{4}{|l|}{ Social Support } \\
\hline \multicolumn{4}{|l|}{ Partner helps my efforts ${ }^{t}$} \\
\hline Helps my efforts ${ }^{n, m}$ & \multirow{2}{*}{ NS } & \multirow{2}{*}{ NS } & \multirow{2}{*}{ NS } \\
\hline $\begin{array}{l}\text { Neither helps nor inhibits my efforts/ inhibit my } \\
\text { efforts } n, m\end{array}$ & & & \\
\hline Partner also follows program ${ }^{\mathrm{t}}$ & NS & NS & NS \\
\hline Partner lost weight ${ }^{\mathrm{t}}$ & NS & NS & NS \\
\hline Family started to eat better ${ }^{\mathrm{t}}$ & NS & NS & NS \\
\hline Conversations with friends, co-workers, or relatives ${ }^{\mathrm{t} 1,2}$ & \multirow{3}{*}{ NS } & $<0.0001$ & 0.0024 \\
\hline Disagree or Neutral ${ }^{n, m}$ & & (15) $1.1 \pm 13.7$ & (15) $4.9 \pm 16.1$ \\
\hline Agree $^{n, m}$ & & (40) $19.6 \pm 14.5$ & (40) $19.9 \pm 15.2$ \\
\hline Conversations with my doctors $^{\rho}$ & \multirow{3}{*}{ NS } & \multirow{3}{*}{ NS } & 0.0276 \\
\hline Disagree or Neutral ${ }^{n, m}$ & & & (32) $11.7 \pm 16.8$ \\
\hline Agree $^{n, m}$ & & & (23) $21.7 \pm 14.9$ \\
\hline \multicolumn{4}{|l|}{ Behavioral Support from Dietitian ${ }^{\beta 3}$} \\
\hline Health coach call frequency & NS & $3.2191(0.006)$ & NS \\
\hline Average health coach call & NS & $0.5532(0.020)$ & NS \\
\hline Time with an RDN (MNT + Health coach call) & NS & $0.0747(0.010)$ & NS \\
\hline$\%$ Of different SMART goals met & NS & $0.1607(0.001)$ & $0.1037(0.025)$ \\
\hline
\end{tabular}

Abbreviations: Fat-Free Mass Index (FFMI); Healthy Eating Index Scores (HEI); Registered Dietitian Nutritionist (RDN); Medical Nutrition Therapy (MNT); SMART (Specific, Measurable, Attainable, Realistic, Time-bound); Not Significant (NS). $\beta$ Simple linear regression analysis was done on pairs of continuous variables, value reported estimate of slope $\beta$ (p-value). $\rho$ Nonparametric correlation analysis (Spearman's Rho) was used for ordinal variables (dietary self-Monitoring, weekly weight self-monitoring, partner has lost weight, conversations with my doctors, with three or more ordinal levels vs. HEI (W0, change W6, change W12). t Variable pairs with categorical independent variables (self-efficacy, partner helps my weight loss efforts, partner also follows program, family started to eat better, conversations with friends, co-workers, or relatives, and conversations with my doctors) vs. HEI (W0, change W6, change W12) were analyzed by t-test [n, m (n) Means \pm SD]. 1 Agree (Agree or Strongly Agree), Disagree or Neutral (Strongly Disagree or Disagree + Neutral). 2 (About weight loss strategies I have learned in this program). 3 For $\Delta$ HEI W6, the behavioral support from the RDN was used at 6 week only, while the other response variables, the behavioral support from the RDN was used at 12 week. 